Ecomorphological divergence drives differential mercury bioaccumulation in polymorphic European whitefish (Coregonus lavaretus) populations of subarctic lakes

Kahilainen, Kimmo K.

2017-12-01

Kahilainen , K K , Thomas, S M , Nystedt , E K M , Keva , O, Malinen , T \& Hayden , B 2017 , ' Ecomorphological divergence drives differential mercury bioaccumulation in polymorphic European whitefish (Coregonus lavaretus) populations of subarctic lakes ', The Science of the Total Environment, vol. 599-600 , pp. 1768-1778 . https://doi.org/10.1016/j.scitotenv.2017.05.099

http://hdl.handle.net/10138/307285

https://doi.org/10.1016/j.scitotenv.2017.05.099

cc_by_nc_nd

acceptedVersion

Downloaded from Helda, University of Helsinki institutional repository.

This is an electronic reprint of the original article.

This reprint may differ from the original in pagination and typographic detail.

Please cite the original version. 


\section{Ecomorphological divergence drives differential mercury bioaccumulation in polymorphic European whitefish (Coregonus lavaretus) populations of subarctic lakes}

Kimmo K. Kahilainen ${ }^{* a, b}$, Stephen M. Thomas ${ }^{\mathrm{a}, \mathrm{c}}$, Elina K.M. Nystedt ${ }^{\mathrm{a}}$, Ossi Keva ${ }^{\mathrm{a}}$, Tommi Malinen ${ }^{\mathrm{a}}$, \& Brian Hayden ${ }^{\mathrm{d}}$

aDepartment of Environmental Sciences, University of Helsinki, P.O.Box 65, FIN-00014, Finland

${ }^{\text {b} K i l p i s j a ̈ r v i ~ B i o l o g i c a l ~ S t a t i o n, ~ K a ̈ s i v a r r e n t i e ~ 14622, ~ F I N-99490 ~ K i l p i s j a ̈ r v i, ~ F i n l a n d ~}$

${ }^{c}$ current address: Department of Fish Ecology and Evolution, EAWAG Swiss Federal Institute of Aquatic Science and Technology, Center for Ecology, Evolution and Biogeochemistry, Seestrasse 79, CH-6047 Kastanienbaum, Switzerland.

${ }^{\mathrm{d}}$ Canadian Rivers Institute, Biology Department, University of New Brunswick, Fredericton, NB E3B 5A3, Canada

* Corresponding author: E-mail address: kimmo.kahilainen@helsinki.fi

\section{Highlights}

- Resource polymorphism is typical for many salmonid fish inhabiting subarctic lakes

- Total mercury; THg was related to gill-rakers, age and diet in polymorphic whitefish

- $\mathrm{THg}$ was high in pelagic morphs, intermediate in profundal and low in littoral ones

- Monomorphic whitefish generally had low $\mathrm{THg}$ related to lake-specific factors

- THg transfer and bioaccumulation studies should consider resource polymorphism 


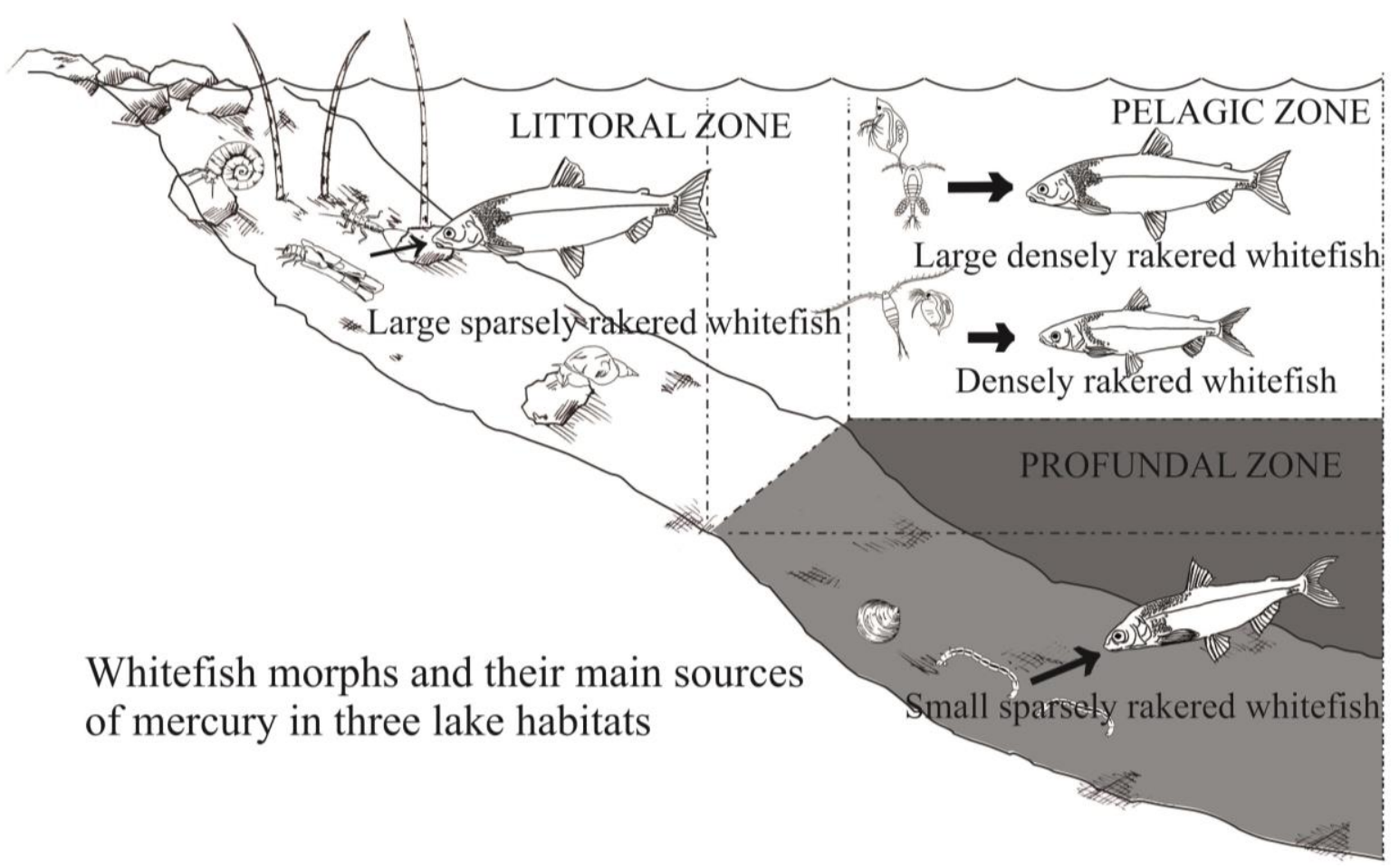

\section{Abstract}

Resource polymorphism, whereby ancestral trophic generalists undergo divergence into multiple specialist morphs, is common in salmonid fish populations inhabiting Subarctic lakes. However, the extent to which such resource specialization into the three principal lake habitats (littoral, profundal, and pelagic) affects patterns of contaminant bioaccumulation remains largely unexplored. Here, we assessed total mercury concentrations (THg) of European whitefish (Coregonus lavaretus (L.)) and their invertebrate prey in relation to potential explanatory variables across 6 Subarctic lakes, of which three are inhabited by polymorphic (comprised of four morphs) and three by monomorphic populations. Amongst invertebrate prey, the highest $\mathrm{THg}$ concentrations were observed in profundal benthic macroinvertebrates, followed by pelagic zooplankton, with concentrations lowest in littoral benthic macroinvertebrates in both lake types. Broadly similar patterns were apparent in whitefish in polymorphic systems, where average age-corrected $\mathrm{THg}$ concentrations and bioaccumulation rates were the highest in pelagic morphs, intermediate in the profundal morph, and the lowest in the littoral morph. 
In monomorphic systems, age-corrected $\mathrm{THg}$ concentrations were generally lower, and showed pronounced lake-specific variation. In the polymorphic systems, we found significant relationships between whitefish muscle tissue THg concentration and gill raker count, resource use, lipid content and maximum length, whilst no such relationships were apparent in the monomorphic systems. Across all polymorphic lakes, the major variables explaining $\mathrm{THg}$ in whitefish were gill raker count and age, whereas in monomorphic systems, the factors were more lake-specific. Whitefish resource polymorphism across the three main lake habitats therefore appears to have profound impacts on $\mathrm{THg}$ concentration and bioaccumulation rate. This highlights the importance of recognizing such intraspecific diversity in both future scientific studies and mercury monitoring programs.

Keywords: Arctic, benthic macroinvertebrates, gill rakers, heavy metals, pelagic zooplankton, stable isotopes

\section{Introduction}

Atmospheric transport is a major source of many organic pollutants and heavy metals in the Arctic regions (Evans et al., 2005; Pacyna et al., 2010; Chételat et al. 2015). Although atmospheric transport and direct deposition of contaminants in terrestrial and aquatic environment is important, there is increasing evidence that recent climate change has enhanced the flux of sequestered substances from catchments to freshwater ecosystems (Stern et al., 2012). Contaminant flux in these regions can also be influenced by the pronounced seasonality of the environment, with toxic substances accumulating in heavy snow cover during the winter, and subsequently entering aquatic ecosystems via meltwater inputs during the following spring. Atmospheric mercury predominantly consists of elemental and inorganic forms, but, following deposition, readily methylates into bioavailable compounds (e.g. methylmercury), 
which characteristically bioaccumulate in organisms and biomagnify in food webs (Downs et al., 1998; Lavoie et al., 2013). Due to the often simple food web structure of Arctic ecosystems, methylmercury may reach high concentrations in top predators across terrestrial, marine, and freshwater habitats (Stern et al., 2012).

In high latitude lakes, atmospheric deposition of mercury (both directly to the lake surface and via leaching from the catchment) is followed by uptake of mercury by pelagic phytoplankton and bacteria, from which it is subsequently transferred to zooplankton, and then to planktivorous fish (Power et al., 2002; Thomas et al., 2016). Previous studies have highlighted the importance of herbivorous cladoceran Daphnia sp. in the transport of methylmercury to fish in high-latitude lakes (Chételat and Amyot, 2009; Kahilainen et al., 2016a). Despite the low mercury content of individual Daphnia, planktivorous fish may consume thousands of individuals per day, potentially explaining their prominent role in mercury transfer pathways (Karimi et al., 2016). In contrast, benthic macroinvertebrates have a broad range of foraging guilds, resulting in differential uptake, complicating mercury transfer processes to fish. As macroinvertebrates inhabit the entire benthic slope, from shallow littoral to deep profundal habitats, they may ultimately derive their energy from either benthic algae and/or terrestrial subsidies near the shore, or from decomposing pelagic seston such as plankton in deeper areas. Due to this difference in basal energy sources, total mercury $(\mathrm{THg})$ concentrations in benthic macroinvertebrates often vary markedly along this axis, being characteristically enriched in profundal taxa relying on decomposing material and thus having a higher trophic position as inferred from stable isotope ratios of nitrogen (Kahilainen et al., 2016a; Thomas et al., 2016).

In fishes, mercury is initially translocated from the stomach via blood to liver (typically bound within proteins) and thereafter to muscle tissue (Oliveira-Ribeiro et al., 1999; Wang and Wang, 2015). In fish muscle, THg consists mostly of methylmercury (MeHg, typically $>90 \%$, in salmonid fish) (e.g. Downs et al., 1998; Riget et al., 2000; Madenjian et al., 2016). Due to the very slow turnover rate of muscle 
tissues in poikilothermic fishes inhabiting low temperature Subarctic and Arctic regions (Hesslein et al., 1993; Hayden et al., 2014; Thomas and Crowther, 2015), positive correlations between muscle THg with fish age and size are common (e.g. Kahilainen et al., 2016a; Thomas et al., 2016). As a consequence of slow growth and high longevity, sexual maturity of fish in high latitude lakes is often delayed relative to their counterparts in warmer regions, resulting in slower, more gradual bioaccumulation (Evans et al., 2005; Blanck and Lamouroux, 2007). Many fish in Subarctic and Arctic lakes are generalist predators, and undergo dietary shifts to maximize use of limited resources, which may obscure ultimate sources of mercury and subsequent transfer pathways in these systems (Evans et al., 2005; Kahilainen et al., 2016a; Thomas et al., 2016). Thus additional biomarkers, such as stable isotope ratios of carbon $\left({ }^{13} \mathrm{C} /{ }^{12} \mathrm{C}\right)$ and nitrogen $\left({ }^{15} \mathrm{~N} /{ }^{14} \mathrm{~N}\right)$, can play an important role in identifying both pelagic-benthic habitat use and the trophic position of consumers, helping elucidate the predominant sources of mercury exposure (e.g. Power et al., 2002; Thomas et al., 2016). Here, $\delta^{13} \mathrm{C}$ is aneffective marker differentiating the typically depleted pelagic phytoplankton-derived food web compartment from the more enriched littoral benthic algae-reliant compartment, whereas $\delta^{15} \mathrm{~N}$ provides a measure of individual trophic position and is often positively related to mercury concentration, at both the species and food web levels of biological organization (Downs et al., 1998; Lavoie et al., 2013; Thomas et al., 2016).

The structural simplicity of food webs characteristic of Subarctic and Arctic lakes makes them useful study systems in which to explore mercury transfer dynamics. The limited fish diversity in these lakes has led to increased ecological opportunity for colonising species, in turn facilitating specialization on either pelagic or benthic resources. Such patterns of divergence are especially common among salmonid fishes, including Arctic charr (Salvelinus alpinus), lake trout (S. namaycush), European whitefish (Coregonus lavaretus), and North American lake whitefish (C. clupeaformis), all of which are prone to diverge into multiple distinct morphs (Jonsson and Jonsson, 2001; Østbye et al., 2006; Bernatchez et al., 2010; Muir et al., 2016). The general pattern of such resource polymorphism is divergence into pelagic and littoral benthic habitats, with associated feeding specialization on zooplankton and benthic 
macroinvertebrates, respectively. However, the evolution of deep-water benthic (hereafter profundal) morphs is more rare (Kahilainen and Østbye, 2006; Knudsen et al., 2006; Chavarie et al. 2016). Despite longstanding knowledge of the presence of both mono- and polymorphic populations across Subarctic and Arctic lakes, far less is known about the ecological variables related to mercury concentrations of different morphs and lake types (but see, Amundsen et al., 2011, Willacker et al., 2013). Putative differences among morphs and lake types may have important repercussions for interpretation of results in long-term mercury monitoring programs and associated human health recommendations, since salmonid species in both lake types often constitute a major focus due to their importance in the diets of indigenous populations across the region (AMAP 2011; van der Velden et al., 2015).

Whitefish is a highly abundant and diverse species, and occurs as polymorphic populations in many highlatitude lakes in northern Fennoscandia (Svärdson, 1979; Østbye et al., 2006; Siwertsson et al., 2010). Lakes with monomorphic populations are most common, followed by systems with divergence into littoral and pelagic habitats, whereas a profundal morph may also arise and co-exist in more complex cases (Kahilainen and Østbye, 2006; Harrod et al., 2010; Siwertsson et al., 2010). At regional scales, polymorphic populations occur in larger, deeper and more productive lakes than monomorphic populations (Siwertsson et al. 2010). In monomorphic lakes, whitefish is a generalist, using all habitat types and foraging on both benthic and pelagic prey (Kahilainen et al., 2007; Harrod et al., 2010). In polymorphic lakes, pelagic morphs feed on zooplankton, whereas littoral and profundal morphs consume benthic macroinvertebrates at different depths (Kahilainen et al., 2004; Kahilainen et al., 2014). Gill raker count is an important morphological trait used for whitefish morph identification as this trait is heritable and correlates with resource use (Svärdson 1979; Kahilainen 2011a,b). In sympatry, morphs show morphological specialization to distinct habitats, where pelagic morphs have a higher number of gill rakers than benthic morphs (Kahilainen and Østbye, 2006; Harrod et al., 2010). The profundal morph, with very few gill rakers, has specialized to the coldest and darkest lake habitat, and has a correspondingly low metabolic rate and low-light phenotypic adaptations (Kahilainen et al., 2014, 
2016b). Resource polymorphism in whitefish may originate from joint effects of ecological speciation and phenotypic plasticity, with variable evidence of genetic differentiation according to neutral microsatellite data highlighting the incipient steps of differentiation (Østbye et al., 2006; Couton, 2012; Praebel et al., 2013). In general, whitefish is a phenotypically plastic species with variable morphology and resource use, especially in monomorphic lakes, where the single generalist morph can be ecomorphologically intermediate between the pelagic and littoral morphs of polymorphic lakes (Kahilainen et al., 2007; Harrod et al., 2010). This ecomorphological diversity of whitefish in both polymorphic and monomorphic lakes provides a very interesting setting to test similarities and differences among morphs and lake types. Although studies of subarctic lakes have to date been limited, zooplankton feeding has been linked to higher rates of mercury accumulation compared to littoral foraging on benthic macroinvertebrates in North American lake whitefish, European whitefish and threespined stickleback (Gasterosteus aculeatus) (Doyon et al., 1998; Amundsen et al., 2011; Willacker et al., 2013). However, previous studies have not explored mercury accumulation in relation to prey concentrations across the three major lake habitats, and have not attempted to assess contrasts between multiple polymorphic and monomorphic systems.

Subarctic lakes in northern Fennoscandia provide excellent study systems in which to assess $\mathrm{THg}$ accumulation in whitefish morphs, due to the occurrence of both polymorphic and monomorphic populations in the same region (Siwertsson et al., 2010). Polymorphic systems are relatively comparable due to the occurrence of morphs diverged across the three principal lake habitats (littoral, profundal, pelagic), whereas monomorphic populations have intermediate morphology and may use all habitat types (Kahilainen et al., 2007; Harrod et al., 2010; Siwertsson et al., 2010). This setting therefore provides an ideal opportunity to assess patterns of ecological divergence, and explore which ecological variables are related to $\mathrm{THg}$ concentration in whitefish. In the present study, we tested three main hypotheses: 
1) Total mercury concentrations in invertebrates groups differ: zooplankton and profundal benthic macroinvertebrates have higher $\mathrm{THg}$ concentrations than littoral benthic macroinvertebrates (Kahilainen et al., 2016a; Thomas et al., 2016). We predicted that THg of whitefish morphs would reflect their main invertebrate prey, whereby pelagic and profundal morphs are more enriched than littoral morphs in polymorphic lakes. Monomorphic populations, using both pelagic and benthic prey, have intermediate mercury concentrations compared to polymorphic populations.

2) We expected to find differences in ecomorphological variables of whitefish morphs in each polymorphic lake, whereas monomorphic populations should display more generalist in resource use (Kahilainen et al., 2007; Harrod et al., 2010; Kahilainen et al., 2014). Pelagic and profundal morphs should bioaccumulate $\mathrm{THg}$ with age at a faster rate than the littoral morph or generalist monomorphic populations. As $\mathrm{THg}$ concentrations are likely to differ among whitefish morphs (Doyon et al., 1998; Amundsen et al., 2011; Blank et al., 2013), we expect that the most important factors explaining THg will include gill raker count, age, size, and resource use.

3) At the population level, we predicted $\mathrm{THg}$ would correlate with resource use, condition, morphology, and life-history traits (age, size, growth, maturity) in all polymorphic systems, but in systems containing a single generalist morph such correlations would be less pronounced.

\section{Materials and methods}

\subsection{Study site and field sampling}

We sampled each of six oligotrophic lakes once within a circa one week period during August-September 2009-2014 (Table 1). These natural lakes, all of which are located in subarctic Fennoscandia, have an ice-free season lasting from May-June to November-December, are well-oxygenated (saturation 66$88 \%$ ), have circumneutral waters ( $\mathrm{pH}$ 6.9-7.2) and low humic content (DOC 1.9-4.8) throughout the 
whole water column (Fig. 1, Table 1). Severe oxygen deficiencies in profundal habitats have not been observed in the study lakes. Catchments generally consist of birch/pine forest and peatland. Lakes Inari, Muddus and Paadar are all relatively large and support polymorphic whitefish populations, consisting of four distinct morphs (Table 1). Conversely, Lakes Kilpis, Kuohkima and Siilas, inhabited by monomorphic whitefish, are more varied in area and depth (Fig. 1, Table 1). In general, all lakes (with the possible exception of the smaller Lake Kuohkima) are large and deep enough to contain different habitat types and in theory all whitefish morphs (Siwertsson et al. 2010). In general, analyses by Siwertsson et al. (2010) indicate that monomorphic lakes tend to be smaller, shallower and have a higher water visibility than polymorphic lakes. In this respect, we suggest that our lakes should well represent the variation present in the larger set of monomorphic lakes in across study region. We do not have current or historical atmospheric mercury deposition data from study sites with which to test the potential influence on results of whitefish morph mercury content. However, we attempted to overcome this problem of potentially different mercury concentration at base of the food web by sampling of primary producers (benthic algae) and whitefish prey items (pelagic and benthic invertebrates) from all lakes. Whitefish dominates the fish fauna of all lakes, although they contain variable amounts of other species (Table 1).

Fish were sampled using a gill net series consisting of eight $1.8 \mathrm{~m}$ high and $30 \mathrm{~m}$ long nets (mesh size $12,15,20,25,30,35,45$ and $60 \mathrm{~mm}$ knot to knot) supplemented with one Nordic multi-mesh net (mesh size range $5.25-55 \mathrm{~mm})$. Gill nets were set overnight ( 10-12 hours) in the three main lake habitat types, i.e. littoral, pelagic and profundal. Each habitat type was sampled a minimum of three times and the location of gill nets were randomly assigned for each habitat type. Following capture, all fish were immediately euthanized via cerebral concussion and chilled on ice. Fish were removed from nets and separated by species and morph based on visual evaluation. Here, whitefish morphs were individually field-identified according to body, head and gill raker shape without habitat information. This has been previously tested and found to be a highly efficient way of identification leading to circa $99 \%$ accuracy 
(Kahilainen and Østbye, 2006; Kahilainen et al., 2014; Thomas et al., 2016). Both monomorphic and polymorphic lakes have large sparsely rakered whitefish (LSR), a large-bodied morph (up to $70 \mathrm{~cm}$ ) with silvery colour, a downturned mouth and an intermediate number of relatively short gill rakers (19-30). LSR whitefish use mainly littoral habitats in polymorphic lakes, but in monomorphic lakes behave as generalists, using all three habitat types (Kahilainen et al., 2007; Harrod et al., 2010). Small sparsely rakered whitefish (SSR) is a small-bodied morph (usually $<25 \mathrm{~cm}$ total length), with very large eyes, a strongly downturned mouth and a very low number of short, widely spaced gill rakers (range 12-21), which inhabits profundal. Large densely rakered whitefish (LDR) is also a large-bodied (up to $60 \mathrm{~cm}$ ), silvery-colored morph, but has more a pointed snout and a larger number of longer, more densely spaced gill rakers (range 29-36) than the LSR morph. Finally, densely rakered whitefish (DR) is a small-bodied $(<20 \mathrm{~cm})$, dark-colored morph with a highly pointed snout, equal length jaws and a high number of fine (range 30-43), long and very densely spaced gill rakers. Gill raker number alone is highly informative phenotypic trait, as it defines overall morphology and it is correlated with both diet and habitat use (Kahilainen and Østbye, 2006; Harrod et al., 2010). A high number of long and densely spaced gill rakers is related to pelagic habitat use and a predominantly zooplankton-based diet, whereas a low number of short and widely spaced rakers are related to benthic habitat and foraging of large sized bottom-dwelling invertebrates (Kahilainen et al., 2011a).

To assess THg concentration level at the base of food web i.e. primary producers, we collected biofilm samples from the surface of littoral stones (sampling depth 0-0.5 m) using a brush. Generally, these lakes are too oligotrophic allow for collection of phytoplankton samples for THg analyses, but we did obtain a phytoplankton sample from a single lake (Muddus) using a wind drifting aggregate with a $50 \mu \mathrm{m}$ mesh hand net. Pelagic zooplankton and benthic invertebrates, which are the main prey for whitefish, were sampled from pelagic, littoral and profundal habitats to assess the mercury concentration. Zooplankton were sampled using a $250 \mu \mathrm{m}$ mesh net, via a series of semi-horizontal tows from depths of 0-5 m over the deep pelagic habitat representing structurally simple habitat. In contrast, benthic macroinvertebrates 
from the structurally complex littoral zone requires multiple methods to cover different whitefish prey taxa. Here, we collected macroinvertebrates by hand from hard stony substrates at depths of 0-0.5 m, whereas a kick-net (mesh-size $500 \mu \mathrm{m}$ ) was used in gravel, sand, soft sediment and macrophyte beds at depths of 0-1 m. In addition, soft sediment samples were collected with an Ekman grab (surface area 272 $\mathrm{cm}^{2}$ ) in the littoral zone from $1 \mathrm{~m}$ depth. In the structurally more simple profundal zone, we collected macroinvertebrates with Ekman grab only from depths between 15 to $30 \mathrm{~m}$, depending on maximum depth of lake. All benthic macroinvertebrate samples were sieved through a $500 \mu \mathrm{m}$ mesh on site. Algae samples were rinsed and sieved through 500, 250 and $50 \mu \mathrm{m}$ mesh to avoid any unwanted sediment or invertebrate material in the sample. Upon return to the field laboratory, phytoplankton, benthic algae and bulk pelagic zooplankton samples (composed of cladocerans Bosmina sp. and Daphnia sp. as well as copepods Calanoida and Cyclopoida) were stored in $2 \mathrm{ml}$ plastic vials and frozen $\left(-20{ }^{\circ} \mathrm{C}\right)$. Benthic macroinvertebrates were sorted to the lowest feasible taxonomic level and stored in the same way for taxon specific $\mathrm{THg}$ and isotope analyses. Littoral samples with sufficient individuals to facilitate $\mathrm{THg}$ and stable isotope analyses included Lymnaea sp., Dytiscidae, Corixidae, Trichoptera, Plecoptera, Ephemeroptera, Tipulidae, Oligochaeta and Chironomidae. Profundal samples included Chironomidae, Oligochaeta and Hydracarina. Both pelagic and benthic invertebrate taxa sampled are typical in subarctic lakes and whitefish diet (Kahilainen et al., 2003, 2005, 2007). Shortly after initial freezing, these samples were freeze-dried at $-70{ }^{\circ} \mathrm{C}$ for $48 \mathrm{~h}$.

\subsection{Life-history traits and diet analyses}

Total length (accuracy $0.1 \mathrm{~cm})$ and wet mass $(0.1 \mathrm{~g})$ of each fish was measured. We selected and individually coded circa 30 specimens of each whitefish morph, according to the length distribution of catch, for the subsequent analyses. Fulton's condition factor for each individual was calculated (Nash et al., 2006):

$\mathrm{CF}=\mathrm{W} / \mathrm{TL}^{3 *} 100$, 
where $\mathrm{CF}$ is a condition factor, $\mathrm{W}$ is fish wet mass in grams, TL is fish total length in centimeters. Generally in fishes, a value of ca. 1 is considered as a normal condition, whereas fusiform fish such as whitefish in subarctic region will often receive values ranging from 0.6 to 0.9 (Hayden et al., 2015).

Both sagittal otoliths and circa 50 scales from between the pelvic and anal fins were taken to improve the accuracy of age determination (Kahilainen et al., 2003). One burned and cracked otolith and one clear were inspected under a preparation microscope, whereas scales were pressed on polycarbonate slides and viewed with a microfiche reader. The joint method using two otoliths and scales increases the accuracy of aging and all analysis was conducted by a single experienced reader. Age determination was based on synthesised evaluations from all three bony structures, as has been recommended based on intercalibration tests with European whitefish (Raitaniemi et al., 1998). A non-linear growth model was used to calculate growth rate and maximum size metrics for whitefish morph populations in each lake (von Bertalanffy, 1938):

$L_{t}=L_{\infty}\left\lfloor 1-e^{-K\left(t-t_{0}\right)}\right\rfloor$,

where $L_{t}$ is the estimated total length $(\mathrm{cm})$ at time $t, L_{\infty}$ is the asymptote total length (i.e. theoretical maximum size of fish), $K$ is the growth rate at which the fish is approaching asymptote total length, and $t_{o}$ is the hypothetical starting length at time $O$ according to the model. It should be noted that a high $K$ value means a fast growth to asymptote total length, and is not directly related to large body size of fish. We did not attempt to fit models for hypotheticalzero values for length and age.

The first left gill arch was dissected, cleaned and the number of gill rakers (including small rudimentary rakers at both ends) counted under a preparation microscope. Previous work with these European whitefish morphs has identified gill raker count as highly stable trait throughout the species' ontogeny (Kahilainen, 2004). It should be noted that our whitefish data consisted of fish larger than $\sim 8 \mathrm{~cm}$ TL, where counting of gill rakers is a highly accurate (Kahilainen, 2004), and we thus consider our morph 
classifications reliable for all size categories in the current work. The body cavity was subsequently opened to visually determine sex and sexual maturity for later determination of minimum length and age of sexual maturity for each population. The stomach, from the oesophagus to the pyloric caeca, was dissected out and a point method was used for visual diet determination (Hynes, 1950). Here, stomach fullness was determined using a scale from 0 to 10 , where 0 is an empty and 10 is fully extended. Prey items were identified to the lowest feasible taxonomic level and the relative proportion of each prey category to stomach fullness was visually estimated. Mean stomach fullness and number of empty stomachs were then calculated for each morph. Despite the simplicity of this point method in dietary analyses, we consider these results highly relevant in assessment of consumed prey categories in comparison to sampled invertebrate prey from the study lakes.

\subsection{Stable isotopes and total mercury analyses}

To assess longer term resource use of whitefish morphs, we sampled muscle for carbon and nitrogen stable isotope analyses, which can be used infer patterns of pelagic-benthic habitat use and trophic position, respectively. We dissected a piece of white dorsal muscle from each individual, which was stored in a $2 \mathrm{ml}$ plastic vial and frozen $\left(-20{ }^{\circ} \mathrm{C}\right)$. Samples were subsequently freeze-dried at $-70{ }^{\circ} \mathrm{C}$ for $48 \mathrm{~h}$. Both fish and invertebrate samples were ground, circa 0.5-1.0 mg was encapsulated in tin cups and processed using an elemental analyser (Flash EA 1112) coupled to a continuous-flow isotope ratio mass spectrometer (Thermo Finnigan Delta ${ }^{\text {PLUS }}$ Advantage). Vienna PeeDee Belemnite and atmospheric nitrogen were used as international reference standards for carbon and nitrogen stable isotope ratios, respectively. Each fifth sample consisted of repeated measures of an internal standard (dorsal muscle of pike for animals or potato leaf for plants). Analytical error, determined from the analyses of laboratory standards, for both $\delta^{13} \mathrm{C}$ and $\delta^{15} \mathrm{~N}$ was $\sim 0.1 \%$. The elemental carbon to nitrogen ratio $(\mathrm{C}: \mathrm{N})$ was derived from the percent carbon and nitrogen content of each sample. The $\mathrm{C}: \mathrm{N}$ ratio was used as a proxy for a 
lipid content, where a value of three indicates lipid free muscle tissue and higher values increasing amount of lipids (e.g. Kahilainen et al., 2016a).

$\mathrm{THg}$ concentrations in both fish muscle and invertebrate samples were measured using a direct mercury analyser (Milestone DMA-80). Circa 20-30 mg of freeze-dried homogenized tissue was weighed, and a duplicate was processed for each sample. The average $\mathrm{THg}$ difference $(\% \pm \mathrm{SD})$ between duplicates was 0.41 \pm 0.29 . All runs began and ended with a blank control (average $\mathrm{THg} \mu \mathrm{g} \mathrm{g}^{-1} \mathrm{~d} . \mathrm{w} . \pm \mathrm{SD}, 0.001 \pm 0.003$, $\mathrm{n}=74)$ and certified reference material (CRM, DORM-4, 0.410 $\left.\pm 0.55 \mu \mathrm{g} \mathrm{g}^{-1}\right)$. The average recovery $( \pm \mathrm{SD})$

of CRM was $94.2 \pm 1.3 \%(n=74)$. The average of blank controls in each run was subtracted from measured fish and invertebrate values to reduce the influence of instrument error. The average value of each duplicate pair was then used in all subsequent analyses.

\subsection{Invertebrate prey $\mathrm{THg}$ and bioaccumulation in whitefish morphs (H1)}

We pooled data within lake type (polymorphic and monomorphic), due to low benthic algae and invertebrate sample sizes per lake, to test overall $\mathrm{THg}$ concentration differences via ANOVA and Tukey's HSD pairwise comparisons. When data were not normally distributed, we used $\log (\mathrm{x}+1)$ transformations before testing.

\subsection{Life-history trait and resource use correlation with $\mathrm{THg}$ content (H2)}

Size and morphology related traits (total length, mass, condition, gill raker count and age) were first analysed using principal component analysis (PCA), to test how morphs in different lakes were clustered in multidimensional space. Differences in fish total length, mass, condition and age among whitefish morph populations (total $\mathrm{n}=15$; i.e. four each per polymorphic lake, and one per monomorphic lake) were tested using ANOVA and Tukey's HSD pairwise comparisons with lake as a nested effect. THg concentrations, gill raker count, stable isotope and $\mathrm{C}: \mathrm{N}$ ratios among populations were tested with 
ANCOVA using age as covariate. Bioaccumulation of THg with fish age was explored using univariate linear regression analyses, with individual regressions used for each morph in each lake.

The relative influence of the possible explanatory variables, i.e. total length, condition factor, age, sex (coded as $1=$ female, $2=$ male, $3=$ juvenile), sexual maturity $(0=$ immature, $1=$ mature $)$, number of gill rakers, stable isotope, and $\mathrm{C}: \mathrm{N}$ ratios, in relation to $\mathrm{THg}$ in whitefish dorsal muscle, was assessed using multiple linear regression analysis, via a stepwise forward selection procedure (with entry limit $\mathrm{p}<0.05$ ). Analyses were first run for each lake individually, and subsequently pooled based on lake type (polymorphic vs. monomorphic).

\subsection{Major ecological and life-history factors related to THg in whitefish (H3)}

We tested the population-level relationships between ecomorphological variables and age-corrected $\mathrm{THg}$ concentrations using linear regression analysis separately for all polymorphic and monomorphic lakes. A similar limit for statistical significance $(\mathrm{p}<0.05)$ was used in all analyses. All analyses were conducted using SYSTAT 11 (SYSTAT Software Inc, Chicago, IL, USA), except PCA, which was conducted using Base statistics in R ver. 3.2.2 (R Core Team, 2015).

\section{Results}

\subsection{Average THg of invertebrates and whitefish (H1)}

The average $\mathrm{THg}\left(\mu \mathrm{g} \mathrm{g}^{-1}\right.$ dry weight) of different invertebrate groups was variable among the lake habitats (Table 2). Although sample sizes were too small for statistical testing within lakes, the average 
$\mathrm{THg}$ among invertebrate groups differed in the combined dataset from both polymorphic lakes (ANOVA, $\mathrm{F}_{2,34}=20.8, \mathrm{p}<0.001$ ) and monomorphic lakes (ANOVA, $\mathrm{F}_{2,34}=19.3, \mathrm{p}<0.001$ ), where $\mathrm{THg}$ was higher in profundal benthic macroinvertebrates (Tukey's HSD tests, $\mathrm{p}<0.05$ ) than in other groups. In both lake types (monomorphic ANOVA, $\mathrm{F}_{2,34}=43.7$, $\mathrm{p}<0.001$; polymorphic ANOVA, $\mathrm{F}_{2,34}=44.3$, $\mathrm{p}<0.001$ ), littoral invertebrates were significantly enriched in ${ }^{13} \mathrm{C}$ relative to profundal and pelagic invertebrates (Tukey's HSD tests, $\mathrm{p}<0.05)$. All groups differed significantly from one another in $\delta^{15} \mathrm{~N}$ in both lake types (monomorphic ANOVA, F2,34=31.9, p<0.001; polymorphic ANOVA, $\mathrm{F}_{2,34}=20.4$, p<0.001), with profundal invertebrates most enriched, pelagic zooplankton intermediate and littoral invertebrates most depleted (Tukey’s HSD tests, $\mathrm{p}<0.05$ ). All pairwise comparisons of invertebrate groups and benthic algae between polymorphic and monomorphic lakes were non-significant, except for the higher value C:N ratio of zooplankton in monomorphic lakes (Tukey’s HSD test, $\mathrm{p}<0.05$ ).

\subsection{Life-history traits and resource use of whitefish morphs (H2)}

Principal component analysis revealed that whitefish morphs were clustered with respect to the first two PCA axes, which together explained $82 \%$ of the total variation (Supporting information, Fig. S1). PC1 $(62 \%)$ was positively related to total length, mass, condition and age, whereas PC2 (20\%) was negatively correlated with gill raker number and size (Supporting information, Table S1). ANCOVAs assessing traits separately indicated that gill raker number differed among the morphs (ANCOVA: age, F1,434=4.2, $\mathrm{p}=0.041 ;$ morph $\left.\mathrm{F}_{14,434}=332.0, \mathrm{p}<0.001\right)$ : profundal SSR whitefish had the lowest number (17-18), littoral LSR whitefish were intermediate (22-24), whilst the pelagic morphs, LDR whitefish (32-34) and DR whitefish (35-37), had the highest number of gill rakers (Table 3). The average number of gill rakers in monomorphic LSR whitefish was 25 (Table 3). Whitefish morphs differed in both body size and condition factor (ANOVAs for total length: $F_{9,435}=56.7$, $p<0.001$; mass: $F_{13,435}=19.9$, $p<0.001$; condition: $\left.\mathrm{F}_{12,435}=30.2, \mathrm{p}<0.001\right)$, where $\mathrm{DR}$ whitefish had the lowest average size and condition, and smallest 
maximum size in all three polymorphic lakes, followed by SSR whitefish, which showed similar trends (Table 3; Supporting information Fig. S2). LSR and LDR whitefish had the largest body sizes among the morphs in all polymorphic lakes, coupled with higher condition factors and the largest maximum size. Body size, condition, growth and the maximum size of LSR whitefish were relatively similar between the mono- and polymorphic lakes (Table 3; Supporting information Fig. S2). DR whitefish had the smallest size at sexual maturity, followed by SSR whitefish (Table 3). The large-bodied LSR and LDR morphs matured at a larger size than the other morphs (Table 3). THg concentrations of whitefish differed among populations (ANCOVA: age; $F_{1,434}=318.6, p<0.001$ morph; $F_{14,434}=49.3, p<0.001$ ). In all polymorphic lakes, littoral LSR had the lowest levels $\left(0.20-0.24 \mu \mathrm{g} \mathrm{g}^{-1}\right)$, profundal SSR were intermediate (0.31-0.36 $\left.\mu \mathrm{g} \mathrm{g}^{-1}\right)$, whereas pelagic LDR $\left(0.40-0.48 \mu \mathrm{g} \mathrm{g}^{-1}\right)$ and DR $\left(0.49-0.60 \mu \mathrm{g} \mathrm{g}^{-1}\right)$ had the highest age-corrected concentrations (Table 3). In the monomorphic lakes, LSR whitefish in Lakes Kilpis $\left(0.18 \mu \mathrm{g} \mathrm{g}^{-1}\right)$ and Siilas $\left(0.28 \mu \mathrm{g} \mathrm{g}^{-1}\right)$ had $\mathrm{THg}$ levels comparable to LSR whitefish in the polymorphic lakes, whereas concentrations in Lake Kuohkima $\left(0.37 \mu \mathrm{g} \mathrm{g}^{-1}\right)$ monomorphic LSR exceeded these (Table 3).

The diet of whitefish morphs was related to their habitat use and gill raker number. SSR whitefish exclusively fed on benthic prey items (composed mainly of Pisidium sp. clams, chironomid larvae and benthic Megacyclops copepods, Hydracarina), whereas LSR whitefish typically used a range of littoral benthic prey such as insect larvae (Chironomidae, Megaloptera, Ephemeroptera, Trichoptera), snails (Lymnaea sp., Valvata sp.) and the benthic cladoceran Eurycercus sp., except in Lake Paadar, where surface insects and zooplankton were also important (Supporting information Table S2). The diet of both LDR and DR whitefish was composed mainly of pelagic prey (95-100\%). LDR whitefish also used adult insects captured from the lake surface in addition to zooplankton, whereas DR whitefish used zooplankton (Bosmina, Daphnia, Calanoida, Cyclopoida) almost exclusively in all lakes (Supporting information Table S2). LSR whitefish in monomorphic lakes used all habitat types and prey items 
mentioned above, where pelagic zooplankton prey typically composed roughly $40-50 \%$ of the total diet, with benthic prey comprising the rest (Supporting information Table S2).

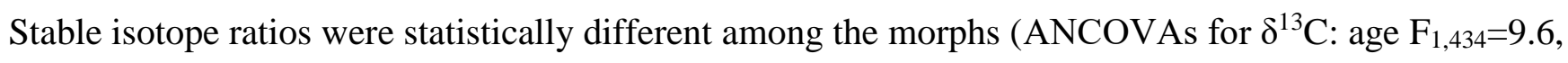
$\mathrm{p}=0.002 ;$ morph $\mathrm{F}_{14,434}=44.5, \mathrm{p}<0.001 ; \delta^{15} \mathrm{~N}$ : age $\mathrm{F}_{1,434}=92.7, \mathrm{p}<0.001 ;$ morph $\left.\mathrm{F}_{14,434}=130.9, \mathrm{p}<0.001\right)$, and within-lake differences between morphs were often pronounced (Table 3). Pelagic DR whitefish and profundal SSR whitefish had similar $\delta^{13} \mathrm{C}$ values, however. SSR whitefish were enriched in ${ }^{15} \mathrm{~N}$ compared to other the morphs. There were also differences in $\mathrm{C}: \mathrm{N}$ ratios among the morphs (ANCOVA, age $\mathrm{F}_{1,434}=5.6, \mathrm{p}=0.019$, morph; $\left.\mathrm{F}_{14,434}=13.3, \mathrm{p}<0.001\right)$, where pelagic DR and LDR whitefish had generally higher ratios than benthic LSR and SSR morphs (Table 3).

THg accumulated with whitefish age in most of the lakes (Fig. 2, Table S3). A pronounced $\mathrm{THg}$ accumulation with age was consistent in pelagic DR and LDR whitefish, whereas benthic littoral LSR whitefish and profundal SSR whitefish had shallower regression slopes, that were often non-significant (Fig. 2, Table S3). THg accumulation in LSR whitefish in monomorphic lakes closely followed patterns observed in LSR whitefish in polymorphic lakes.

In stepwise multiple regression analyses, the most important variables explaining $\mathrm{THg}$ levels in whitefish were more uniform in polymorphic than in monomorphic systems (Table S4). Multiple regression models on the data from the polymorphic lakes explained $62-82 \%$ of the total variation using 3-4 factors, with gill raker count and age proving consistently important. In monomorphic lakes, models explained 35$73 \%$ of the variation using 1-2 lake-specific factors $\left(\delta^{13} \mathrm{C}\right.$, age and sex $)$. The marked difference between lake types was indicated in the combined models, where $71 \%$ of the variation was explained by eight factors in polymorphic lakes, compared to $39 \%$ in monomorphic lakes explained by three factors (Table S4). 
At the population level, we tested univariate linear relationships between $\mathrm{THg}$ concentrations and response variables in both lake types, of which six showed a statistically significant relationship in polymorphic lakes (Fig. 3). THg was positively related to gill raker number, proportion of pelagic prey, $\mathrm{C}: \mathrm{N}$ ratio and was negatively related to $\delta^{13} \mathrm{C}$, maximum theoretical length and PC2 in polymorphic lakes. However, no such statistically significant relationships were apparent in the monomorphic systems.

\section{Discussion}

Results supported our initial hypotheses, as ecomorphology and THg concentrations among the whitefish morphs followed broadly similar patterns in all three polymorphic lakes. Conversely, patterns in generalist LSR whitefish inhabiting the monomorphic lakes were more variable. In all polymorphic lakes, the pelagic, zooplankton-feeding DR and LDR morphs had the highest $\mathrm{THg}$ concentrations and bioaccumulation rates with age, with the profundal benthivore SSR morph intermediate, and lowest levels observed in the littoral benthivore LSR morph. In monomorphic lakes, THg concentrations in LSR whitefish varied between those observed in LSR and SSR whitefish in polymorphic lakes. The most common variables related to $\mathrm{THg}$ concentrations in whitefish in polymorphic lakes were gill raker count and age, whereas in monomorphic lakes, variables appeared more lake-specific. 


\subsection{Zooplankton is important source of $\mathrm{THg}(\mathrm{HI})$}

We found major differences in THg concentrations in the invertebrate groups studied: profundal macroinvertebrates had very high concentrations, whereas pelagic zooplankton were intermediate, and the lowest levels of all were observed in littoral macroinvertebrates. THg concentrations likely reflect exposure via differing energy sources, with profundal invertebrates receiving higher inputs from decomposing plankton and decaying organic material from the benthic slope, as evidenced by their high $\delta{ }^{15} \mathrm{~N}$ value. This ${ }^{15} \mathrm{~N}$ enrichment of profundal macroinvertebrates was further detected in a higher SSR whitefish $\delta^{15} \mathrm{~N}$ value in all three polymorphic lakes compared to other morphs. Recycling of organic material or use of decomposer bacteria within the lake sediments may also contribute to the levels observed in profundal invertebrates, and sediment-dwelling fauna such as chironomid larvae may contain significant amounts of inorganic mercury (Suchanek et al., 2008). Although we lacked MeHg measurements, the relatively low $\mathrm{THg}$ concentration in muscle tissue of the main profundal invertebrate predator, SSR whitefish, suggests that THg of these invertebrates may contain a large proportion of inorganic mercury. In contrast, pelagic zooplankton, especially cladocerans, are filter feeders that consume phytoplankton and bacteria potentially rich in MeHg (Suchanek et al., 2008; Chetelat and Amyot, 2009). In addition, filter feeding zooplankton perform diel vertical migrations in polymorphic lakes, which may further influence mercury fluxes from profundal to pelagic zones, assuming that methylation actively occurs in profundal habitat and the thermocline (Kahilainen et al., 2009). Littoral benthic macroinvertebrates, such as molluscs and large insect larvae, often feed on benthic algae, which were low in THg content. In general, we found broadly similar THg values for the same habitat type in both monomorphic and polymorphic lakes. Such differences in THg concentrations among invertebrate prey groups in all lakes would therefore influence differential habitat specific exposure rates in the whitefish morphs. 


\subsection{Pelagic whitefish morphs have higher THg than benthic ones (H2)}

We found the highest THg concentration in pelagic LDR and DR whitefish, both of which consume zooplankton. Profundal SSR whitefish feeding predominantly on benthic macroinvertebrates, such as chironomid larvae and Pisidium mussels, had intermediate $\mathrm{THg}$, whereas LSR whitefish using more diverse benthic macroinvertebrate prey in shallow littoral areas had 2-3 times lower concentrations than pelagic morphs. These results suggest that the $\mathrm{THg}$ concentration of prey likely explain the higher $\mathrm{THg}$ concentrations apparent in pelagic morphs in comparison to littoral morphs, but do not explain the intermediate concentrations in profundal morphs. THg in whitefish muscle is mainly (circa 90\%) composed of $\mathrm{MeHg}($ Madenjian et al., 2016). Benthic macroinvertebrates can contain a significant proportion of inorganic $\mathrm{Hg}$, which does not effectively translocate to fish muscle during assimilation, and is instead excreted via feces (Oliveira-Ribeiro et al., 1999; Suchanek et al., 2008). Doyon et al. (1998) observed similarly high THg in a pelagic dwarf morph of lake whitefish, and much lower concentrations in a large littoral morph. They did not find a clear link with prey THg concentrations, however, instead hypothesizing that the variation was due to metabolic differences between morphs.

Trudel et al. (2001) modeled such metabolic differences between lake whitefish morphs and found a very high metabolic rate in a pelagic dwarf morph, with correspondingly high $\mathrm{THg}$ concentrations in comparison to a large littoral morph. Furthermore, the pelagic morph matures at a smaller size and $\mathrm{THg}$ accumulates in muscle rather than gonads (Doyon et al., 1998; Madenjian et al., 2016). This dwarf lake whitefish morph represents an almost exact ecomorphological analogue of the DR whitefish in our study, which also showed rapid $\mathrm{THg}$ bioaccumulation with age. The other pelagic morph, larger, later-maturing and faster-growing LDR whitefish, reached a slightly lower concentrations of age-corrected THg. Both grow quickly until maturation, suggesting high pelagic zooplankton consumption and high metabolic energy demand. The putatively lower per unit energy content of zooplankton compared to benthic macroinvertebrates, and subsequently increased consumption, may further enhance their exposure 
compared to benthic morphs (Karimi et al., 2016). Zooplankton foraging also requires more active swimming to capture evasive prey compared to foraging on more sedentary benthic prey, increasing the metabolic cost for pelagic morph (Trudel et al., 2001). Large-growing and late-maturing littoral LSR whitefish had significantly lower $\mathrm{THg}$ concentrations, suggesting that combined effects of lower $\mathrm{THg}$ concentration in littoral prey and lower rate of food consumption must play a role in explaining differences between LSR and LDR whitefish. The most peculiar morph, small-sized and late-maturing profundal SSR whitefish, fed on invertebrates with high $\mathrm{THg}$ concentration, but only reached intermediate mercury concentrations, lending further support to the role of low food consumption and low metabolic rate in cold temperature habitats with scant prey resources (Trudel et al., 2001; Bernatchez et al., 2010; Karimi et al., 2016). Differences in THg concentration among whitefish morphs could, therefore, be at least partly related to metabolic differences, in addition to prey $\mathrm{THg}$ content. This is supported by variable respiration rates amongst morphs, as estimated from otolith microchemistry, which follow the order (from the highest to lowest): DR, LDR, LSR and SSR whitefish (Kahilainen et al., 2014). Monomorphic populations had generally low $\mathrm{THg}$ concentrations, equating to values intermediate between LSR and SSR whitefish in polymorphic lakes. THg concentration of monomorphic LSR whitefish seemed to be negatively related to lake size. This suggests that mercury may be more concentrated in lake with a smaller water volume, although we did not get a consistent evidence from invertebrate prey concentrations. However, invertebrate $\mathrm{THg}$ concentrations are subject to seasonal variation and our snap-shot sampling is likely relevant only to differences among habitat types.

We found that $\mathrm{THg}$ of whitefish in monomorphic lakes was relatively poorly explained (39\%) by factors including $\delta^{13} \mathrm{C}$, sex and age, reflecting lake-specific differences among whitefish and their prey. In contrast, results from polymorphic lakes were more directly comparable, with gill raker count and age positively related to $\mathrm{THg}$ across all systems. In combination, pooled data from all lakes revealed the most 
prominent relationships were in gill raker count, age and sexual maturity, which were all positively related to $\mathrm{THg}$, whereas total length and $\delta^{13} \mathrm{C}$ were negatively related to $\mathrm{THg}$. Our results indicated that mercury transfer to fish is enhanced via specialization on pelagic resources, whereas more generalist resource use in monomorphic whitefish led to lower concentrations. Our results somewhat deviate from those previously reported for alpine whitefish populations, where total length was positively related to $\mathrm{MeHg}$, but gill raker count did not explain relative concentrations (Blank et al., 2013), with this likely due to differences in lake characteristics and morph types between both regions. More generally, increasing size, age, and maturity stage result in higher $\mathrm{THg}$, as has been documented for many salmonids, including coregonids, across a diverse range of habitats and geographic locations (e.g. Doyon et al., 1998, Riget et al., 2000; Blank et al., 2013; Thomas et al., 2016).

\subsection{THg correlates with ecomorphological metrics in whitefish morphs (H3)}

Divergence into distinct littoral and pelagic morphs is typical for many fish species inhabiting postglacial lakes (Skulasson and Smith, 1995), and salmonid fish are especially prone to intricate ecomorphological divergence into multiple morphs along benthic and pelagic depth clines (Kahilainen and Østbye, 2006; Vonlanthen et al., 2009; Knudsen et al., 2016; Muir et al., 2016). In whitefish, gill raker traits play a crucial role in determining morph-specific foraging ecology, with benthivorous morphs typically characterized by few, small, and widely spaced gill rakers, whereas planktivores have many, long, and tightly spaced gill rakers (Kahilainen et al., 2011). We found that both gill raker count and pelagic resource use were positively correlated with $\mathrm{THg}$ in polymorphic lakes, whereas no clear patterns were found in generalist monomorphic LSR populations. Pelagic resource use was also related to higher lipid content, as identified via positive correlation between $\mathrm{C}: \mathrm{N}$ ratio and $\mathrm{THg}$ in polymorphic populations. As mercury is bound to proteins and lipids contain very little mercury (e.g. Amlund et al., 2007), the 
differences between pelagic and benthic morphs would have been even more pronounced with lipidcorrected values using arithmetic C:N ratio based correction (Kahilainen et al., 2016a). Such lipid correction of THg was not performed, however, as we aimed to directly test correlations between C:N ratio and THg. Pelagic resource use has been often linked to higher THg levels in fish in subarctic lakes (Power et al., 2002; Amundsen et al., 2011; Thomas et al., 2016) and thus our results from polymorphic whitefish corroborate previous studies. Many other studies have shown positive correlation between $\mathrm{THg}$ and $\delta^{15} \mathrm{~N}$ indicating bioaccumulation with increasing trophic level of species. The lack of such clear correlation in our study indicates that whitefish are feeding at the same trophic level consuming pelagic or benthic invertebrates. Although, SSR whitefish has higher $\delta^{15} \mathrm{~N}$ values than other morphs, this relates to feeding on profundal invertebrates relying on energy from above pelagic plankton remains and thus having enriched $\delta^{15} \mathrm{~N}$ values (Hayden et al., 2015). In general, LSR whitefish in monomorphic systems use a combination of both pelagic and benthic resources, grow steadily to a large size and mature late. However, THg correlations were not observed in monomorphic lakes, at least partly due to the limited number of populations studied. Despite the small number of lakes sampled, observed ecomorphological trait patterns of monomorphic populations in this study are typical for the region.

\subsection{Mercury monitoring, fish consumption, and human health}

We found considerable variation (as much as $2-3$ fold) in average THg concentration among whitefish morphs in polymorphic lakes, suggesting that long-term mercury monitoring results may be biased if morph definition is not taken into account. As polymorphism is typical for whitefish throughout its distribution, it is important to classify pelagic and benthic morphs when analyzing mercury concentration data for whitefish. Despite the pronounced differences among the morphs and lakes, THg concentrations in all measured whitefish individuals were below Finnish national health authorization limits (i.e. $0.5 \mu \mathrm{g}$ $\mathrm{g}^{-1}$ wet weight; approx. 2.0-2.5 $\mu \mathrm{g} \mathrm{g}^{-1}$ dry weight). Indigenous whitefish fisheries in the study region 
focus mainly on large-bodied morphs (LSR and LDR whitefish), which had the lowest and highest average THg concentrations, respectively. Although there seems to be no immediate health risks based on reported average fish consumption levels, this may be complicated by often high year-round fish consumption frequency by indigenous people, coupled with indirect pathways via consumption of piscivorous fish that predate whitefish (Thomas et al., 2016). Whitefish is the dominant fish species in these lakes and the central node in food webs (Kahilainen et al., 2004; Harrod et al., 2010; Thomas et al., 2016). The small-bodied pelagic DR whitefish is the most abundant morph and may reach very high population density in the pelagic zone, compared to the much lower density reached by other sympatric morphs or monomorphic LSR whitefish (Jensen et al., 2008; Kahilainen et al., 2011b; Malinen et al., 2014). In polymorphic lakes, DR whitefish with high $\mathrm{THg}$ are heavily consumed by all piscivorous species, and represent an especially important forage fish for pelagic brown trout (Salmo trutta) and Arctic charr, both of which are also a highly preferred catch in local fisheries (Kahilainen and Lehtonen, 2003; Kahilainen et al., 2009; Jensen et al., 2015). The key role of DR whitefish as a forage fish in polymorphic lakes suggest that pelagically-derived $\mathrm{THg}$ is efficiently transferred to piscivorous fish, which may themselves subsequently exceed the aforementioned health limits (Thomas et al., 2016). In monomorphic lakes, predators also consume generalist whitefish (Jensen et al., 2008, 2015), but due to low $\mathrm{THg}$ concentrations in such populations, they may not reach equivalently high levels as in polymorphic lakes. However, whole food web mercury studies of comparable monomorphic and polymorphic systems would be essential to shed further light on ecosystem-level consequences of resource polymorphism for mercury biomagnification. This would also provide a highly necessary examination of contemporary food web reliance on pelagic and benthic energy sources which, based on the present study, have a clear impacts on $\mathrm{THg}$ accumulation patterns. Accelerating climate change in subarctic regions and associated increases in temperature and precipitation are likely to increase lake productivity, shifting food webs towards pelagically-derived energy and mercury sources (Rolls et al., 2017). However, climate change also affects all levels of biological organization and can facilitate the 
invasion of new species via range expansion to subarctic lakes, further complicating such simple predictions derived from temperature and productivity only (Hayden et al., 2017; Rolls et al., 2017).

\subsection{Conclusions}

In conclusion, we documented clear relationships between gill raker number, resource use, and age with $\mathrm{THg}$ concentration in polymorphic lakes, suggesting similar processes were operating across these systems. In contrast, monomorphic systems containing only generalist LSR whitefish displayed more lake-specific patterns. We found consistent differences in $\mathrm{THg}$ concentration among populations of polymorphic whitefish, with the highest concentrations and bioaccumulation rates documented in pelagic morphs with high gill raker counts and predominantly zooplankton-based diets, whereas benthic morphs had lower concentrations and bioaccumulation rates. Such patterns appeared inherently related to differences in $\mathrm{THg}$ concentrations between different invertebrate prey, but may also partly originate from differential metabolic and food consumption rates among the whitefish morphs. Gill raker count and age were important factors related to $\mathrm{THg}$ concentration in all polymorphic lakes, whereas monomorphic lakes did not show a similar consistency, suggesting lake-specific differences. However, the consistent differences in $\mathrm{THg}$ concentrations and bioaccumulation rates between morphs utilizing the three different lake habitats suggests that similar processes may be important in other polymorphic systems across the circumpolar Arctic.

\section{Acknowledgements}

We thank the numerous people that participated in field sampling and laboratory work over the course of the study. Kilpisjärvi Biological Station and Muddusjärvi Research Station kindly provided field work facilities. Funding for this work was provided by Academy of Finland (projects 1140903 and 1268566 
to KKK) and Finnish Cultural Foundation (NEKM). Mr. Pekka Antti-Poika kindly provided the linedrawings presented in the graphical abstract.

\section{References}

AMAP 2011: AMAP Assessment 2011: Mercury in the Arctic. Arctic Monitoring and Assessment Programme (AMAP), Oslo, Norway.

Amlund, H., Lundebye, A.-K., Berntssen, M.H.G., 2007. Accumulation and elimination of methylmercury in Atlantic cod (Gadus morhua L.) following dietary exposure. Aquat. Toxicol. 83, 323330.

Amundsen, P.-A., Kashulin, N.A., Terentjev, P., Gjelland, K.Ø., Koroleva, I.M., Dauvalter, V.A., et al., 2011. Heavy metal contents in whitefish (Coregonus lavaretus) along a pollution gradient in a subarctic watercourse. Env. Monit. Assessm. 182, 301-316.

Bernatchez, L., Renaut, S., Whiteley, A.R., Derome, N., Jeukens, J., Landry, L., et al., 2010. On the origin of species: insights from the ecological genomics of lake whitefish. Philos. T. R. Soc. B. 365, 1783-1800.

von Bertalanffy, L., 1938. A quantitative theory of organic growth (inquiries on growth laws II). Human Biol. 10, 181-213.

Blanck, A., Lamouroux, N., 2007. Large-scale intraspecific variation in life-history traits of European freshwater fish. J. Biogeogr. 34, 862-875.

Blank, N., Hudson, A.G., Vonlanthen, P., Seehausen, O., Hammerschmidt, C.R., Senn, D.B., 2013. Speciation leads to divergent methylmercury accumulation in sympatric whitefish. Aquat. Sci. 75, 261273. 
Chavarie, L., Harrford, W.J., Howland, K.L., Fitzsimons, J., Muir, A.M., Krueger, C.C. et al., 2016. Multiple generalist morphs of lake trout: avoiding constraints on the evolution of intraspecific divergence? Ecol. Evol. 6, 7727-7741.

Chételat, J., Amyot, M., 2009. Elevated methylmercury in High Arctic Daphnia and the role of productivity in controlling their distribution. Glob. Change Biol. 15, 706-718.

Chételat, J., Amyot, M., Arp, P., Blais, J.M., Depew, D., Emmerton, C.A., et al., 2015. Mercury in freshwater ecosystems of the Canadian Arctic: Recent advances on its cycling and fate. Sci. Total Environ. 509-510, 41-66.

Couton, M., 2012. Adaptive radiation of the European whitefish, Coregonus lavaretus (L.), in the Pasvik watercourse: the genetic description of a new morph. MSc thesis, University of Troms $\varnothing$, Troms $\emptyset$.

Doyon, J-F., Schetagne, R., Verdon, R., 1998. Different mercury bioaccumulation rates between sympatric populations of dwarf and normal lake whitefish (Coregonus clupeaformis) in the La Grande complex watershed, James Bay, Québec. Biogeochemistry 40, 203-216.

Downs, S.G., Macleod, C.L., Lester, J.N., 1998. Mercury in precipitation and its relation to bioaccumulation in fish: a literature review. Water Air Soil Poll. 108, 149-187.

Evans, M.S., Muir, D., Lockhart, W.L., Stern, G., Ryan, M., Roach, P., 2005. Persistent organic pollutants and metals in the freshwater biota of the Canadian Subarctic and Arctic: An overview. Sci. Total Environ. 351-352, 94-147.

Harrod, C., Mallela, J., Kahilainen, K.K., 2010. Phenotype-environment correlations in a putative whitefish adaptive radiation. J. Anim. Ecol. 79, 1057-1068.

Hayden, B., Harrod, C., Kahilainen, K.K., 2014. Dual-fuels: intra-annual variation in the relative importance of benthic and pelagic resources to maintenance, growth and reproduction in a generalist salmonid fish. J. Anim. Ecol. 83, 1501-1512. 
Hayden, B., Harrod, C., Sonninen, E., Kahilainen, K.K., 2015. Seasonal depletion of resources intensifies trophic interactions in subarctic freshwater fish communities. Freshw. Biol. 60, 1000-1015.

Hayden, B., Myllykangas J-P., Rolls, R.J., Kahilainen, K.K., 2017. Climate and productivity shape fish and invertebrate community structure in subarctic lakes. Freshw. Biol. 62, 990-1003.

Hesslein, R.H., Hallard, K.A., Ramlal, P., 1993. Replacement of sulfur, carbon, and nitrogen in tissues of growing broad whitefish (Coregonus nasus) in response to a change in diet traced by $\mathrm{d}^{34} \mathrm{~S}, \mathrm{~d}^{13} \mathrm{C}$, and $d^{15}$ N. Can. J. Fish. Aquat. Sci. 50, 2071-2076.

Hynes, H.B.N., 1950. The food of freshwater sticklebacks (Gasterosteus aculeatus and Pygosteus pungitius), with a review of methods used in studies of the food of fishes. J. Anim. Ecol. 19, 36-58.

Jensen, H., Kahilainen, K.K., Amundsen, P-A., Gjelland, K.Ø., Tuomaala, A., Malinen, T., et al., 2008. Predation by brown trout (Salmo trutta) along a diversifying prey community gradient. Can. J. Fish. Aquat. Sci. 65, 1831-1841.

Jensen, H., Kahilainen, K.K., Vinni, M., Gjelland, K.Ø., Malinen, T., Harrod, C., et al., 2015. Food consumption rates of piscivorous brown trout (Salmo trutta) foraging on contrasting coregonid prey. Fish. Manag. Ecol. 22, 295-306.

Jonsson, B., Jonsson, N., 2001. Polymorphism and speciation in Arctic charr. J. Fish Biol. 58, 605-638.

Kahilainen, K. 2004. Ecology of sympatric whitefish (Coregonus lavaretus (L.)) forms in a subarctic lake. $\mathrm{PhD}$ thesis. University of Helsinki. Department of Biological and Environmental Sciences.

Kahilainen, K., Lehtonen, H. 2003. Piscivory and prey selection of four predator species in a whitefish dominated subarctic lake. J. Fish Biol. 63, 659-672. 
Kahilainen, K., Lehtonen, H., Könönen, K., 2003. Consequence of habitat segregation to growth rate of two sparsely rakered whitefish forms (Coregonus lavaretus (L.)) in a subarctic lake. Ecol. Freshw. Fish $12,275-285$.

Kahilainen, K., Malinen, T., Tuomaala, A., Lehtonen, H., 2004. Diel and seasonal habitat and food segregation of three sympatric Coregonus lavaretus forms in a subarctic lake. J. Fish Biol. 64, 418-434.

Kahilainen, K., Alajärvi, E., Lehtonen, H., 2005. Planktivory and diet-overlap of densely rakered whitefish (Coregonus lavaretus (L.)) in a subarctic lake. Ecol. Freshw. Fish 14, 50-58.

Kahilainen, K., Østbye, K., 2006. Morphological differentiation and resource polymorphism in three sympatric whitefish Coregonus lavaretus (L.) forms in a subarctic lake. J. Fish Biol. 68, 63-79.

Kahilainen, K.K., Malinen, T., Tuomaala, A., Alajärvi, E., Tolonen, A., Lehtonen, H., 2007. Empirical evaluation of phenotype-environment correlation and trait utility with allopatric and sympatric whitefish, Coregonus lavaretus (L.), populations in subarctic lakes. Biol. J. Linn. Soc. 92, 561-572.

Kahilainen, K.K., Malinen, T., Lehtonen, H., 2009. Polar light regime and piscivory govern diel vertical migrations of planktivorous fish and zooplankton in a subarctic lake. Ecol. Freshw. Fish 18, 481-490.

Kahilainen, K.K., Siwertsson, A., Gjelland, K.Ø., Knudsen, R., Bøhn, T., Amundsen, P-A., 2011a. The role of gill raker number variability in adaptive radiation of coregonid fish. Evol. Ecol. 25, 573-588.

Kahilainen, K.K., Østbye, K., Harrod, C., Shikano, T., Malinen, T., Merilä, J. 2011b. Species introduction promotes hybridization and introgression in Coregonus: is there sign of selection against hybrids? Mol. Ecol. 20, 3838-3855.

Kahilainen, K.K., Patterson, W.P., Sonninen, E., Harrod, C., Kiljunen, M., 2014. Adaptive radiation along a thermal gradient: preliminary results of habitat use and respiration rate divergence among whitefish morphs. PloS ONE 9, e112085. 
Kahilainen, K.K., Thomas, S.M., Keva, O., Hayden, B., Knudsen R., Eloranta A.P., et al., $2016 a$. Seasonal dietary shift to zooplankton influences stable isotope ratios and total mercury concentrations in Arctic charr (Salvelinus alpinus (L.)). Hydrobiologia 783, 47-63.

Kahilainen, K.K., Smura, T., Knudsen, R., Amundsen, P-A., Jokela-Määttä, M., Donner, K., $2016 b$. Visual pigments of Arctic charr (Salvelinus alpinus (L.)) and whitefish (Coregonus lavaretus (L.)) morphs in subarctic lakes. Hydrobiologia 783, 223-237.

Karimi, R., Chen, C.Y., Folt, C.L., 2016. Comparing nearshore benthic and pelagic prey as mercury sources to lake fish: the importance of prey quality and mercury content. Sci. Total Environ. 565, 211221.

Knudsen, R., Klemetsen, A., Amundsen, P-A., Hermansen, B., 2006. Incipient speciation through niche expansion: an example from the Arctic charr in a subarctic lake. Proc. R. Soc. B. 273, 2291-2298.

Knudsen, R., Amundsen, P-A., Eloranta, A.P., Hayden, B., Siwertsson, A., Klemetsen, A., 2016. Parallel evolution of profundal Arctic charr morphs in two contrasting fish communities. Hydrobiologia 783, 239-248.

Lavoie, R.A., Jardine, T.D., Chumchal, M.M., Kidd, K.A., Campbell, L.M., 2013. Biomagnification of mercury in aquatic food webs: a worldwide meta-analysis. Environ. Sci. Technology 47, 13385-13394. Madenjian, C.P., Ebener, M.P., Krabbenhoft, D.P., 2016. Mercury accumulation, and the mercury-PCBsex interaction, in lake whitefish (Coregonus clupeaformis). Environments 3, 7.

Malinen, T., Tuomaala, A., Lehtonen, H., Kahilainen, K.K. 2014. Hydroacoustic assessment of monoand polymorphic Coregonus density and biomass in subarctic lakes. Ecol. Freshw. Fish 23, 424-437.

Muir, A.M., Hansen, M.J., Bronte, C.R., Krueger, C.C., 2016. If Arctic charr Salvelinus alpinus is 'the most diverse vertebrate', what is the lake charr Salvelinus namaycush? Fish and Fisheries 17, 1194-1207. 
Nash, R.D., Valencia, A.H., Geffen, A.J. 2006. The origin of Fulton's condition factor - setting the record straight. Fisheries 31, 236-238.

Oliveira Ribeiro, C.A., Rouleau, C., Pelletier, E., Audet, C., Tjäve, H., 1999. Distribution kinetics of dietary methylmercury in the Arctic charr (Salvelinus alpinus). Environ. Sci. Technology 33, 902-907.

Østbye, K., Amundsen, P. A., Bernatchez, L., Klemetsen, A., Knudsen, R., Kristoffersen, R., et al., 2006. Parallel evolution of ecomorphological traits in the European whitefish Coregonus lavaretus (L.) species complex during postglacial times. Mol. Ecol. 15, 3983-4001.

Pacyna, E.G., Pacyna, J.M., Sundseth, K., Munthe, J., Kindbom, K., Wilson, S., et al., 2010. Global emission of mercury to the atmosphere from anthropogenic sources in 2005 and projections to 2020. Atmospheric Environ. 44, 2487-2499.

Power, M., Klein, G.M., Guiguer, K.R.R.A., Kwan, M.K.H., 2002. Mercury accumulation in the fish community of a sub-Arctic lake in relation to trophic position and carbon sources. J. Appl. Ecol. 39, 819830.

Præbel, K., Knudsen, R., Siwertsson, A., Karhunen, M., Kahilainen, K.K., Ovaskainen, O., et al., 2013. Ecological speciation in postglacial European whitefish: rapid adaptive radiations into the littoral, pelagic and profundal lake habitats. Ecol. Evol. 3, 4970-4986.

Raitaniemi, J., Bergstrand, E., Flöystad, L., Hokki, R., Kleiven, E., Rask, M., et al., 1998. The reliability of whitefish (Coregonus lavaretus (L.)) age determination - differences between methods and between readers. Ecol. Freshw. Fish 7, 25-35.

R Core Team, 2015. R: A Language and Environment for Statistical Computing. R Foundation for Statistical Computing, Vienna, Austria.

Riget, F., Asmund, G., Aastrup, P., 2000. Mercury in Arctic charr (Salvelinus alpinus) populations from Greenland. Sci. Total Environ. 245, 161-172. 
Rolls, R.J., Hayden, B., Kahilainen, K.K., 2017. Conceptualising the interactive effects of climate change and biological invasions on subarctic freshwater fish. Ecol. Evol. DOI: 10.1002/ece3.2982

Siwertsson, A., Knudsen, R., Kahilainen, K.K., Præbel, K., Primicerio, R., Amundsen, P-A., 2010. Sympatric diversification as influenced by ecological opportunity and historical contingency in a young species lineage of whitefish. Evol. Ecol. Res. 12, 929-947.

Skulason, S., Smith, T.B., 1995. Resource polymorphism in vertebrates. Trends Ecol. Evol. 10, 366-370.

Stern, G.A., Macdonald, R.W., Outridge, P.M., Wilson, S., Chételat, J., Cole, A., et al., 2012. How does climate change influence arctic mercury? Sci. Total Environ. 414, 22-42.

Suchanek, T.H., Eagles-Smith, C.A., Harner, E.J., 2008. Is Clear Lake methylmercury distribution decoupled from bulk mercury loading? Ecol. Appl. 18, A107-A127.

Svärdson, G., 1979. Speciation of Scandinavian Coregonus. Rep. Inst. Freshw. Res. Drott. 57, 1-95.

Thomas, S.M., Crowther, T.W., 2015. Predicting rates of isotopic turnover across the animal kingdom: a synthesis of existing data. J. Anim. Ecol. 84, 861-870.

Thomas, S.M., Kiljunen, M., Malinen, T., Eloranta, A.P., Amundsen, P-A., Lodenius, M., et al., 2016. Food-web structure and mercury dynamics in a large subarctic lake following multiple species introductions. Freshw. Biol. 61, 500-517.

Trudel, M., Tremblay, A., Schetagne, R., Rasmussen, J.B., 2001. Why are dwarf fish so small? An energetic analysis of polymorphism in lake whitefish (Coregonus clupeaformis). Can. J. Fish. Aquat. Sci. 58, 394-405.

van der Velden, S., Dempson, J.B., Power, M., 2015. Comparing mercury concentrations across a thirty year time span in anadromous and non-anadromous Arctic charr from Labrador, Canada. Sci. Tot. Environ. 509-510, 165-174. 
Vonlanthen, P., Roy, D., Hudson, A.G., Largiader, C.R., Bittner, D., Seehausen, O., 2009. Divergence along a steep ecological gradient in lake whitefish (Coregonus sp.). J. Evol. Biol. 22, 498-514.

Wang, X., Wang, W-X., 2015. Physiologically based pharmacokinetic model for inorganic and methylmercury in a marine fish. Environ. Sci. Technology 49, 10173-10181.

Willacker, J.J., von Hippel, F.A., Ackerly, K.L., O’Hara, T.M., 2013. Habitat-specific foraging and sex determine mercury concentrations in sympatric benthic and limnetic ecotypes of threespine stickleback. Environ. Toxicol. Chem. 32, 1623-1630. 
Table 1. Lake location, morphology, water chemistry and fish fauna. Proportion of coregonid fish (\%) is based on estimates from experimental gill net fishing. Oxygen and temperature in profundal habitats were measured at either $20 \mathrm{~m}$ or the maximum depth in case of shallower lakes.

\begin{tabular}{|c|c|c|c|c|c|c|}
\hline & Inari & Muddus & Paadar & Kilpis & Kuohkima & Siilas \\
\hline Latitude $\left({ }^{\circ} \mathrm{N}\right)$ & 68.58 & 69.00 & 68.52 & 69.03 & 69.03 & 69.04 \\
\hline Longitude $\left({ }^{\circ} \mathrm{E}\right)$ & 27.4 & 26.5 & 26.35 & 20.49 & 20.33 & 20.45 \\
\hline Altitude (m a.s.1.) & 118 & 146 & 144 & 473 & 489 & 484 \\
\hline Area $\left(\mathrm{km}^{2}\right)$ & $1043(32)^{*}$ & 48 & 21 & 37.3 & 0.3 & 1 \\
\hline Maximum depth (m) & $92(40)^{*}$ & 73 & 56 & 57 & 10 & 15 \\
\hline Mean depth (m) & 14.5 & 8.5 & 11.7 & 19.4 & 2.6 & 5.2 \\
\hline Compensation depth (m) & 8 & 6 & 6 & 10 & 8 & 15 \\
\hline Secchi-depth (m) & 6 & 3 & 3 & 10 & 5 & 8 \\
\hline $\mathrm{pH}$ & 7.2 & 7.2 & 7.1 & 7.1 & - & 6.9 \\
\hline $\mathrm{DOC}\left(\mathrm{mg} \mathrm{C} \mathrm{L}{ }^{-1}\right)$ & 4.8 & 4.8 & 4.8 & 2.8 & 3.0 & 1.9 \\
\hline Oxygen saturation (1 m) & 87 & 84 & 88 & 83 & 83 & 82 \\
\hline Oxygen saturation (profundal) & 79 & 66 & 69 & 80 & 78 & 70 \\
\hline Temperature at $1 \mathrm{~m}\left({ }^{\circ} \mathrm{C}\right)$ & 13.5 & 13.6 & 13.5 & 15.3 & 16.3 & 17 \\
\hline Temperature at profundal $\left({ }^{\circ} \mathrm{C}\right)$ & 13.3 & 12.4 & 8.3 & 6.8 & 7.4 & 9.5 \\
\hline $\operatorname{TotP}\left(\mu \mathrm{g} \mathrm{L}^{-1}\right)$ & 5 & 4 & 7 & 4 & 3 & 5 \\
\hline $\operatorname{Tot} \mathrm{N}\left(\mu \mathrm{g} \mathrm{L}^{-1}\right)$ & 150 & 160 & 160 & 120 & 200 & 159 \\
\hline Coregonid fish proportion (\%) & 80 & 86 & 91 & 97 & 89 & 86 \\
\hline Number of fish species & 13 & 10 & 9 & 8 & 6 & 6 \\
\hline
\end{tabular}

* Lake Inari sampling was confined to a single $32 \mathrm{~km}^{2}$ bay (Nanguvuono) 
Table 2. Sample size, total mercury concentration ( $\mathrm{THg} \mu \mathrm{g} \mathrm{g}{ }^{-1}$ dry weight), stable isotope ratios and C:N ratio $( \pm \mathrm{SE})$ of biofilm, phytoplankton (Lake Muddus only) littoral and profundal benthic macroinvertebrates (BMI) and pelagic zooplankton in six study lakes, as well as combined values for all polymorphic and all monomorphic lakes.

\begin{tabular}{|c|c|c|c|c|c|}
\hline Lake and group & $\mathrm{n}$ & $\mathrm{THg}\left(\mu \mathrm{g} \mathrm{g}^{-1}\right)$ & $\delta^{13} \mathrm{C}(\%)$ & $\delta^{15} \mathrm{~N}(\%)$ & $\mathrm{C}: \mathrm{N}$ ratio \\
\hline \multicolumn{6}{|l|}{ Lake Inari } \\
\hline Biofilm & 1 & 0.027 & -28.0 & 3.7 & 12.8 \\
\hline BMI littoral & 7 & $0.050 \pm 0.010$ & $-22.5 \pm 1.4$ & $1.7 \pm 0.6$ & $5.1 \pm 0.2$ \\
\hline BMI profundal & 2 & 0.380 & -32.5 & 6.2 & 6.5 \\
\hline Pelagic zooplankton & 6 & $0.070 \pm 0.004$ & $-30.9 \pm 0.2$ & $3.1 \pm 0.3$ & $4.8 \pm 0.2$ \\
\hline \multicolumn{6}{|l|}{ Lake Muddus } \\
\hline Biofilm & 2 & 0.012 & -17.5 & 1.3 & 13.7 \\
\hline Phytoplankton & 2 & 0.012 & -23.0 & 0.3 & 4.9 \\
\hline BMI littoral & 5 & $0.056 \pm 0.015$ & $-24.4 \pm 1.4$ & $2.6 \pm 0.9$ & $4.6 \pm 0.1$ \\
\hline BMI profundal & 2 & 1.264 & -32.2 & 6.7 & 4.4 \\
\hline Pelagic zooplankton & 3 & $0.105 \pm 0.001$ & $-31.5 \pm 0.4$ & $3.9 \pm 0.9$ & $4.1 \pm 0.1$ \\
\hline \multicolumn{6}{|l|}{ Lake Paadar } \\
\hline Biofilm & 1 & 0.005 & -20.0 & 1.6 & 13.1 \\
\hline BMI littoral & 7 & $0.091 \pm 0.015$ & $-24.6 \pm 1.2$ & $1.3 \pm 0.3$ & $5.3 \pm 0.6$ \\
\hline BMI profundal & 2 & 3.498 & -29.7 & 6.2 & 4.5 \\
\hline Pelagic zooplankton & 3 & $0.077 \pm 0.001$ & $-32.5 \pm 0.1$ & $3.8 \pm 0.1$ & $4.5 \pm 0.1$ \\
\hline \multicolumn{6}{|l|}{ All polymorphic lakes } \\
\hline Biofilm & 4 & $0.014 \pm 0.005$ & $-20.8 \pm 2.5$ & $2.0 \pm 0.6$ & $13.3 \pm 0.2$ \\
\hline BMI littoral & 19 & $0.067 \pm 0.008$ & $-23.8 \pm 0.7$ & $1.8 \pm 0.3$ & $5.0 \pm 0.2$ \\
\hline BMI profundal & 6 & $1.714 \pm 0.968$ & $-31.4 \pm 0.6$ & $6.4 \pm 0.3$ & $5.1 \pm 0.6$ \\
\hline Pelagic zooplankton & 12 & $0.081 \pm 0.005$ & $-31.5 \pm 0.3$ & $3.5 \pm 0.3$ & $4.5 \pm 0.1$ \\
\hline \multicolumn{6}{|l|}{ Lake Kilpis } \\
\hline Biofilm & 3 & $0.007 \pm 0.000$ & $-18.0 \pm 0.2$ & $1.8 \pm 1.0$ & $10.5 \pm 0.2$ \\
\hline BMI littoral & 4 & $0.023 \pm 0.004$ & $-20.8 \pm 0.4$ & $2.3 \pm 0.3$ & $5.0 \pm 0.2$ \\
\hline BMI profundal & 3 & $0.174 \pm 0.080$ & $-28.7 \pm 1.0$ & $6.7 \pm 0.1$ & $5.4 \pm 0.6$ \\
\hline Pelagic zooplankton & 9 & $0.078 \pm 0.003$ & $-31.6 \pm 0.1$ & $4.3 \pm 0.1$ & $5.1 \pm 0.2$ \\
\hline \multicolumn{6}{|l|}{ Lake Kuohkima } \\
\hline Biofilm & 2 & 0.018 & -17.7 & -0.4 & 15.7 \\
\hline BMI littoral & 10 & $0.072 \pm 0.012$ & $-26.9 \pm 0.4$ & $1.8 \pm 0.3$ & $5.1 \pm 0.2$ \\
\hline BMI profundal & - & - & - & - & - \\
\hline Pelagic zooplankton & 3 & $0.075 \pm 0.001$ & $-33.6 \pm 0.03$ & $3.4 \pm 0.1$ & $5.4 \pm 0.03$ \\
\hline \multicolumn{6}{|l|}{ Lake Siilas } \\
\hline Biofilm & 3 & $0.016 \pm 0.001$ & $-24.4 \pm 0.3$ & $0.9 \pm 0.3$ & $13.4 \pm 2.2$ \\
\hline BMI littoral & 3 & $0.037 \pm 0.007$ & $-25 \pm 1.4$ & $1.1 \pm 0.5$ & $5.2 \pm 0.4$ \\
\hline BMI profundal & 2 & 0.410 & -31.3 & 5.6 & 4.6 \\
\hline Pelagic zooplankton & 3 & $0.089 \pm 0.001$ & $-33.6 \pm 0.1$ & $2.7 \pm 0.01$ & $5.2 \pm 0.1$ \\
\hline
\end{tabular}


All monomorphic lakes

Biofilm

BMI littoral

$8 \quad 0.013 \pm 0.002$

$-20.3 \pm 1.2 \quad 0.9 \pm 0.5$

$12.9 \pm 1.1$

BMI profundal

17

$0.055 \pm 0.009$

$-25.1 \pm 0.7 \quad 1.8 \pm 0.2$

$5.1 \pm 0.1$

Pelagic zooplankton

$5 \quad 0.270 \pm 0.086$

$-29.7 \pm 0.9 \quad 6.3 \pm 0.3$

$5.1 \pm 0.4$

$15 \quad 0.080 \pm 0.002$

$-32.4 \pm 0.3 \quad 3.8 \pm 0.2$

$5.2 \pm 0.1$ 
Table 3. The measured mean total mercury concentration (THg raw $\mu \mathrm{g} \mathrm{g}^{-1}$ dry weight) as well as ANCOVA age-corrected (THg age c) and total-length-corrected (THg TL c) values for each morph and lake. Ecomorphological data include means for total length (TL) in cm, wet mass in $\mathrm{g}$, condition factor (CF) and age as raw measured data. The similar age correction as with THg were employed for gill raker count (GR), stable isotope ratios $(\%)$ and $\mathrm{C}: \mathrm{N}$ ratio $(\mathrm{C}: \mathrm{N})$ of whitefish morphs in the six study lakes $( \pm \mathrm{SE})$. Population-level metrics for each whitefish morph include von Bertalanffy growth rate $(K)$, maximum length $\left(L_{\infty}\right)$, minimum total length at sexual maturation (LS) and minimum age at sexual maturity (AS). Whitefish morphs abbreviations: DR; densely rakered whitefish, LDR; large densely rakered whitefish, LSR; large sparsely rakered whitefish, SSR; small sparsely rakered whitefish. Note that Lakes Kilpis, Kuohkima and Siilas contain only the LSR morph.

\begin{tabular}{|c|c|c|c|c|c|c|c|c|c|c|c|c|c|c|c|}
\hline Lake and morph & $\mathrm{n}$ & $\begin{array}{l}\mathrm{THg} \\
\text { raw }\end{array}$ & $\begin{array}{l}\mathrm{THg} \\
\text { age c }\end{array}$ & $\begin{array}{l}\text { THg } \\
\text { TL c }\end{array}$ & $\mathrm{TL}$ & Mass & $\mathrm{CF}$ & Age & $\begin{array}{l}\text { GR } \\
\text { age c }\end{array}$ & $\begin{array}{l}\delta^{13} \mathrm{C} \\
\text { age c }\end{array}$ & $\begin{array}{l}\delta^{15} \mathrm{~N} \\
\text { age c }\end{array}$ & $\begin{array}{l}\mathrm{C}: \mathrm{N} \\
\text { age c }\end{array}$ & $K$ & $L_{\infty}$ & LS \\
\hline \multicolumn{16}{|l|}{ Lake Inari } \\
\hline DR & 31 & $0.43 \pm 0.03$ & $0.49 \pm 0.02$ & $0.53 \pm 0.03$ & $12.6 \pm 0.5$ & $15.5 \pm 2.1$ & $0.66 \pm 0.01$ & $3.9 \pm 0.3$ & $35.5 \pm 0.4$ & $-29.1 \pm 0.3$ & $9.1 \pm 0.1$ & $3.25 \pm 0.01$ & 0.17 & 18.3 & 12.2 \\
\hline LSR & 31 & $0.19 \pm 0.02$ & $0.21 \pm 0.02$ & $0.13 \pm 0.02$ & $28.0 \pm 1$ & $255.6 \pm 41.6$ & $0.86 \pm 0.01$ & $5.7 \pm 0.4$ & $22.4 \pm 0.4$ & $-25.4 \pm 0.3$ & $8.8 \pm 0.1$ & $3.22 \pm 0.01$ & 0.10 & 60.4 & 21.8 \\
\hline SSR & 30 & $0.37 \pm 0.02$ & $0.32 \pm 0.02$ & $0.40 \pm 0.02$ & $20.4 \pm 0.6$ & $68.0 \pm 5.0$ & $0.75 \pm 0.01$ & $8.6 \pm 0.6$ & $18.4 \pm 0.4$ & $-28.5 \pm 0.3$ & $10.5 \pm 0.1$ & $3.22 \pm 0.01$ & 0.17 & 25.5 & 19.1 \\
\hline \multicolumn{16}{|l|}{ Lake Muddus } \\
\hline DR & 29 & $0.51 \pm 0.04$ & $0.60 \pm 0.02$ & $0.60 \pm 0.03$ & $13.7 \pm 0.3$ & $18.4 \pm 1.0$ & $0.70 \pm 0.01$ & $3.1 \pm 0.3$ & $36.0 \pm 0.4$ & $-29.5 \pm 0.3$ & $8.5 \pm 0.1$ & $3.35 \pm 0.01$ & 0.19 & 18.0 & 12.7 \\
\hline LDR & 30 & $0.57 \pm 0.04$ & $0.48 \pm 0.02$ & $0.50 \pm 0.03$ & $30.0 \pm 0.2$ & $221.2 \pm 4.6$ & $0.82 \pm 0.01$ & $10.1 \pm 0.8$ & $33.9 \pm 0.4$ & $-29.1 \pm 0.3$ & $7.6 \pm 0.1$ & $3.31 \pm 0.01$ & 0.46 & 30.6 & 29.2 \\
\hline LSR & 30 & $0.18 \pm 0.02$ & $0.20 \pm 0.02$ & $0.15 \pm 0.02$ & $25.0 \pm 1.0$ & $141.7 \pm 20.5$ & $0.76 \pm 0.01$ & $5.5 \pm 0.6$ & $23.2 \pm 0.4$ & $-26.6 \pm 0.3$ & $7.8 \pm 0.1$ & $3.24 \pm 0.01$ & 0.23 & 34.2 & 21.7 \\
\hline SSR & 29 & $0.38 \pm 0.02$ & $0.34 \pm 0.02$ & $0.43 \pm 0.02$ & $18.2 \pm 0.9$ & $55.6 \pm 9.0$ & $0.74 \pm 0.01$ & $8.1 \pm 0.9$ & $17.2 \pm 0.4$ & $-30.0 \pm 0.3$ & $9.6 \pm 0.1$ & $3.23 \pm 0.01$ & 0.10 & 27.5 & 16.7 \\
\hline \multicolumn{16}{|l|}{ Lake Paadar } \\
\hline DR & 30 & $0.52 \pm 0.02$ & $0.57 \pm 0.02$ & $0.60 \pm 0.03$ & $14.3 \pm 0.2$ & $19.7 \pm 0.9$ & $0.66 \pm 0.01$ & $4.7 \pm 0.3$ & $37.5 \pm 0.4$ & $-29.5 \pm 0.3$ & $9.2 \pm 0.1$ & $3.28 \pm 0.01$ & 0.84 & 14.9 & 11.8 \\
\hline LDR & 29 & $0.58 \pm 0.03$ & $0.48 \pm 0.02$ & $0.51 \pm 0.03$ & $30.5 \pm 0.7$ & $238.2 \pm 13.7$ & $0.80 \pm 0.01$ & $10.5 \pm 0.7$ & $33.9 \pm 0.4$ & $-28.0 \pm 0.3$ & $8.0 \pm 0.1$ & $3.26 \pm 0.01$ & 0.51 & 31.6 & 23.7 \\
\hline LSR & 31 & $0.25 \pm 0.02$ & $0.24 \pm 0.02$ & $0.21 \pm 0.02$ & $26.2 \pm 1.5$ & $178.8 \pm 28.2$ & $0.74 \pm 0.01$ & $6.8 \pm 0.9$ & $24.7 \pm 0.4$ & $-24.6 \pm 0.3$ & $7.4 \pm 0.1$ & $3.19 \pm 0.01$ & 0.15 & 39.7 & 25.3 \\
\hline SSR & 30 & $0.37 \pm 0.02$ & $0.36 \pm 0.02$ & $0.41 \pm 0.02$ & $19.0 \pm 0.8$ & $56.2 \pm 6.8$ & $0.70 \pm 0.01$ & $6.8 \pm 0.8$ & $18.5 \pm 0.4$ & $-30.3 \pm 0.3$ & $9.7 \pm 0.1$ & $3.22 \pm 0.01$ & 0.13 & 28.1 & 20.6 \\
\hline Lake Kilpis & & & & & & & & & & & & & & & \\
\hline $\begin{array}{l}\text { LSR } \\
\text { Lake Siilas }\end{array}$ & 31 & $0.37 \pm 0.04$ & $0.37 \pm 0.02$ & $0.34 \pm 0.02$ & $26.0 \pm 1.5$ & $182.5 \pm 27.9$ & $0.77 \pm 0.02$ & $6.7 \pm 0.8$ & $25.0 \pm 0.4$ & $-25.9 \pm 0.3$ & $6.9 \pm 0.1$ & $3.18 \pm 0.01$ & 0.10 & 44.5 & 29.2 \\
\hline LSR & 29 & $0.21 \pm 0.01$ & $0.28 \pm 0.01$ & $0.18 \pm 0.01$ & $26.1 \pm 1.2$ & $170.3 \pm 29.2$ & $0.77 \pm 0.01$ & $3.8 \pm 0.4$ & $25.1 \pm 0.4$ & $-26.3 \pm 0.3$ & $6.7 \pm 0.1$ & $3.24 \pm 0.01$ & 0.21 & 46.0 & 29.7 \\
\hline
\end{tabular}




\section{Figure legends}

Fig. 1. Map of the northern Fennoscandia (A) showing the location of study lakes with monomorphic (B) or polymorphic (C) whitefish.

Fig. 2. Linear relationships between total mercury concentration and whitefish age by morph in Lakes Inari (a), Muddus (b), Paadar (c), Kilpis (d), Kuohkima (e), and Siilas (f). Whitefish morph abbreviations: DR; densely rakered whitefish, LDR; large densely rakered whitefish, LSR; large sparsely rakered whitefish, SSR; small sparsely rakered whitefish. Note that only significant relationships are indicated in plots. See Table S3 for linear regression statistics.

Fig. 3. Relationship between whitefish THg concentration (age corrected) and population-level gill raker count (a), littoral-pelagic resource use with $\delta^{13} \mathrm{C}(\mathrm{b})$, pelagic diet (c), a lipid content proxy with $\mathrm{C}: \mathrm{N}$ ratio (d), maximum size from von Bertanlanffy non-linear growth model (e) and and ecomorphological score (PC2) from principal component axis 2 (f) in polymorphic (black dots) and monomorphic lakes (white dots). Linear regression statistics are indicated in each figure. 


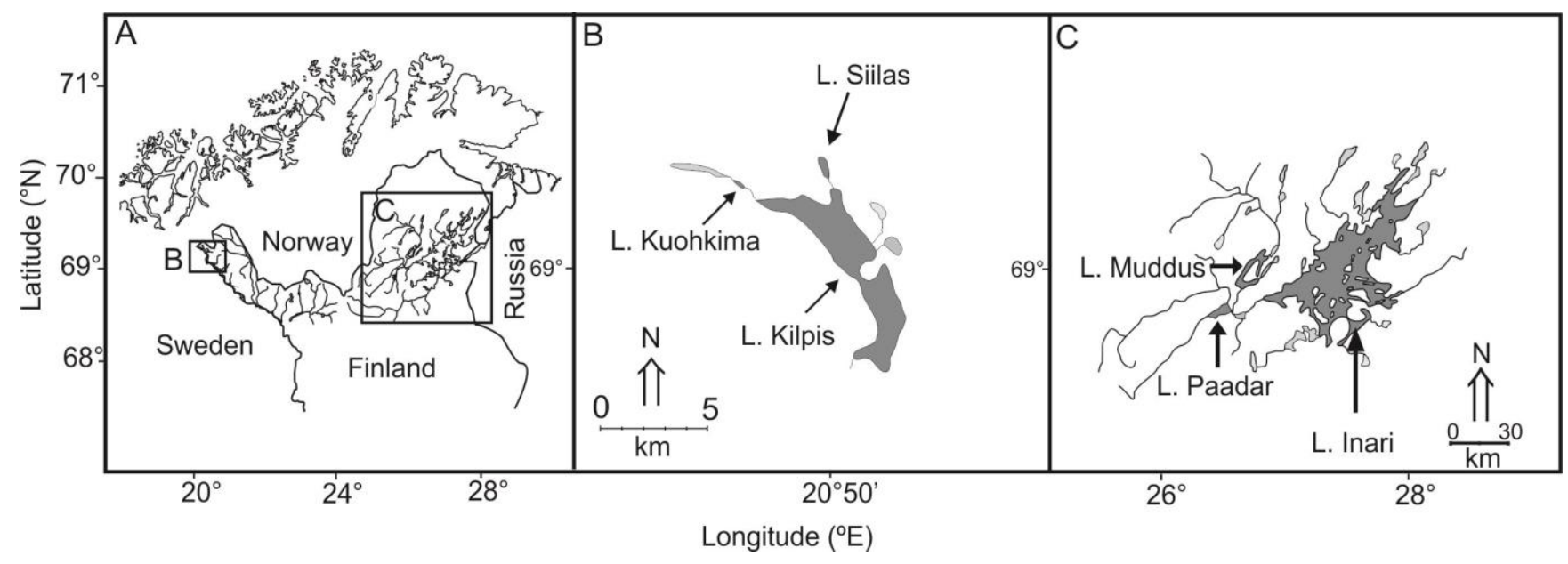

Fig. 1. 

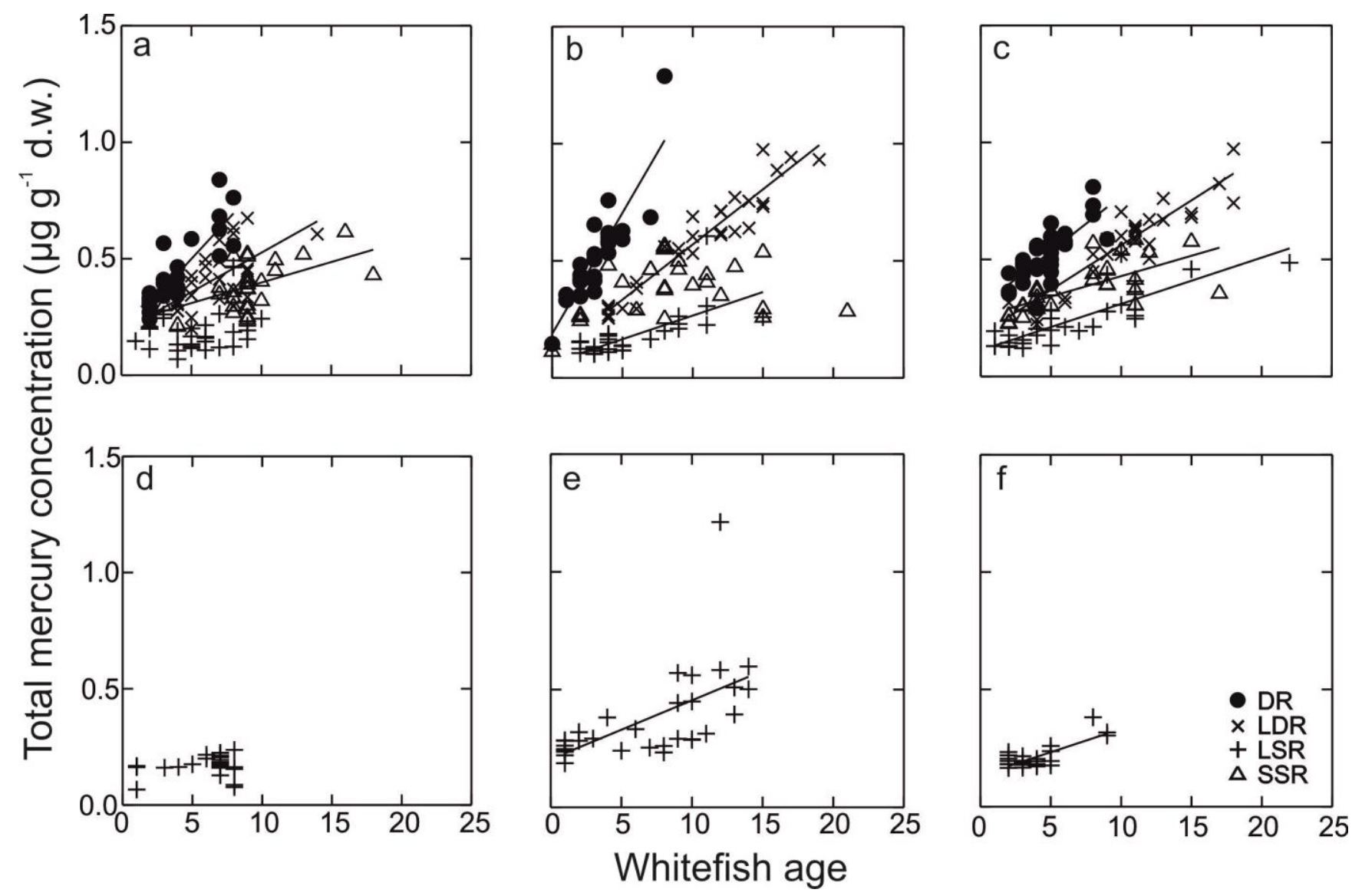

Fig. 2. 

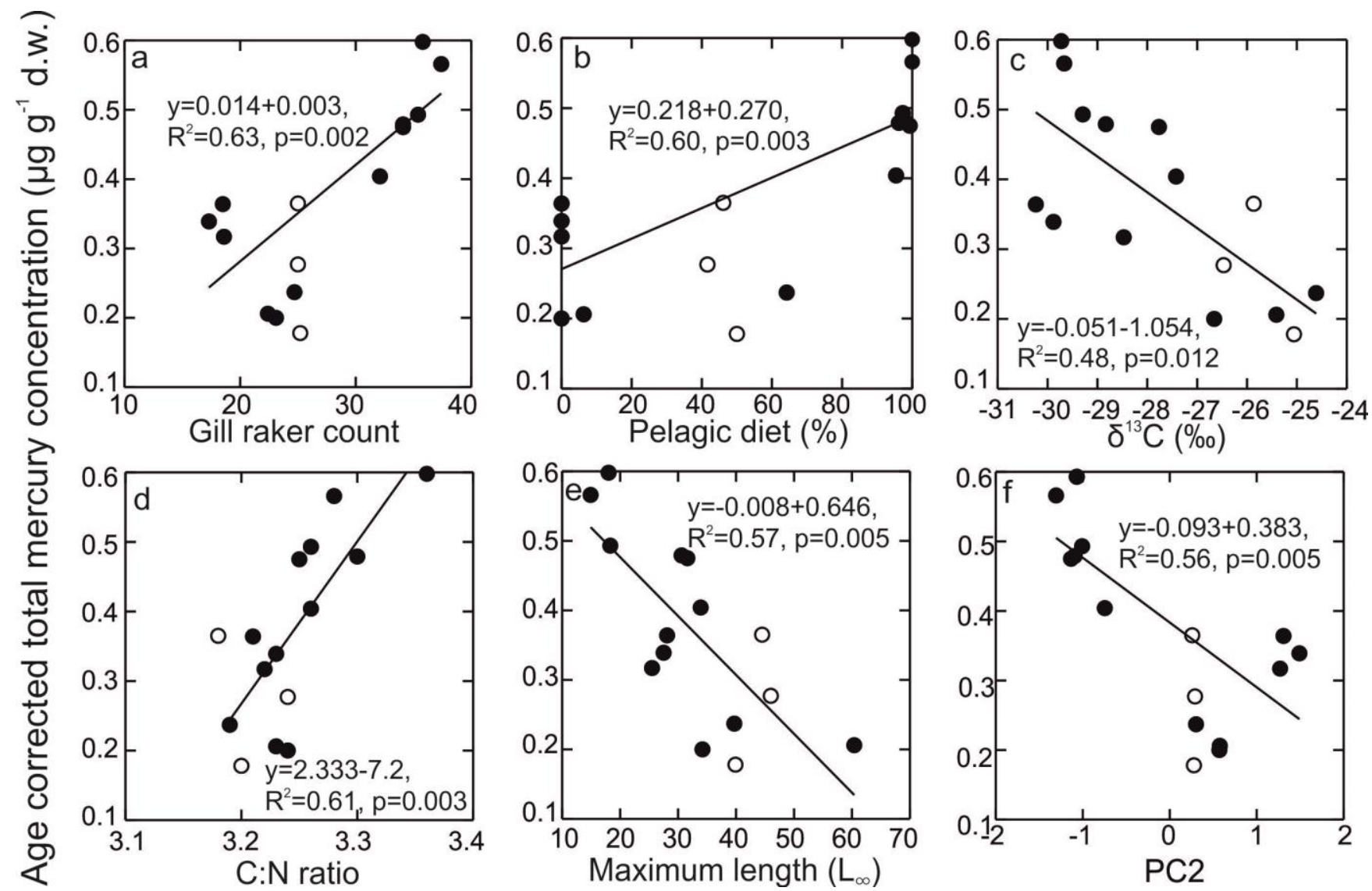

Fig. 3. 


\section{Supporting information}

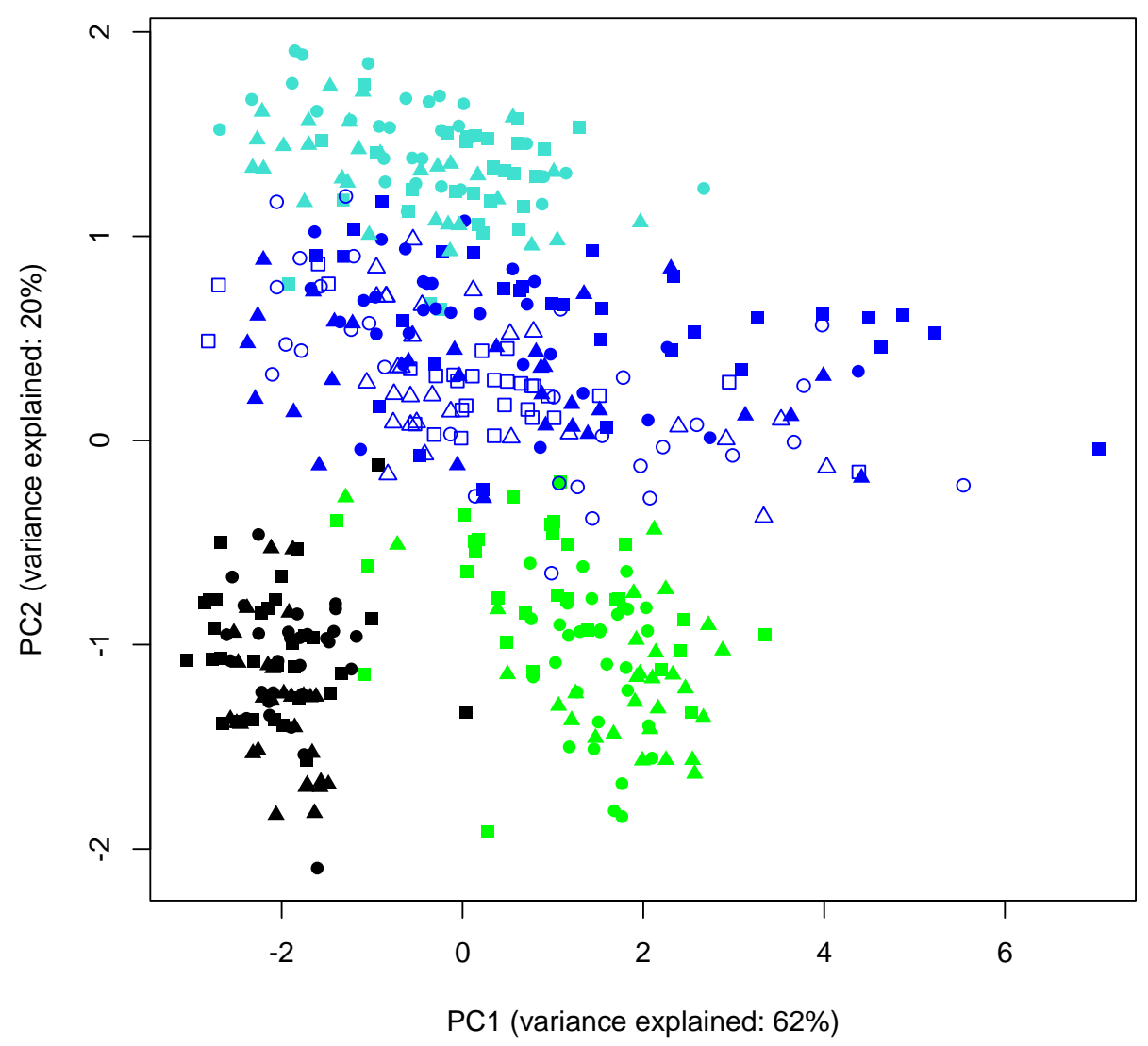

Figure S1. Principal component analysis of ecomorphological traits of whitefish morphs in polymorphic and monomorphic systems. These first two axes (i.e. PC1 and PC2) together explain $82 \%$ of the total variation. Whitefish morphs are indicated with different colours: DR=black, LDR=green, LSR=blue and SSR=turquoise. Lakes are delineated by different symbols: Inari $=$ filled squares, Muddus $=$ filled circles, Paadar $=$ filled triangles, Kilpis $=$ open squares, Kuohkima $=$ open circles, Siilas $=$ open triangles. For the axis loadings, see Table S1. 

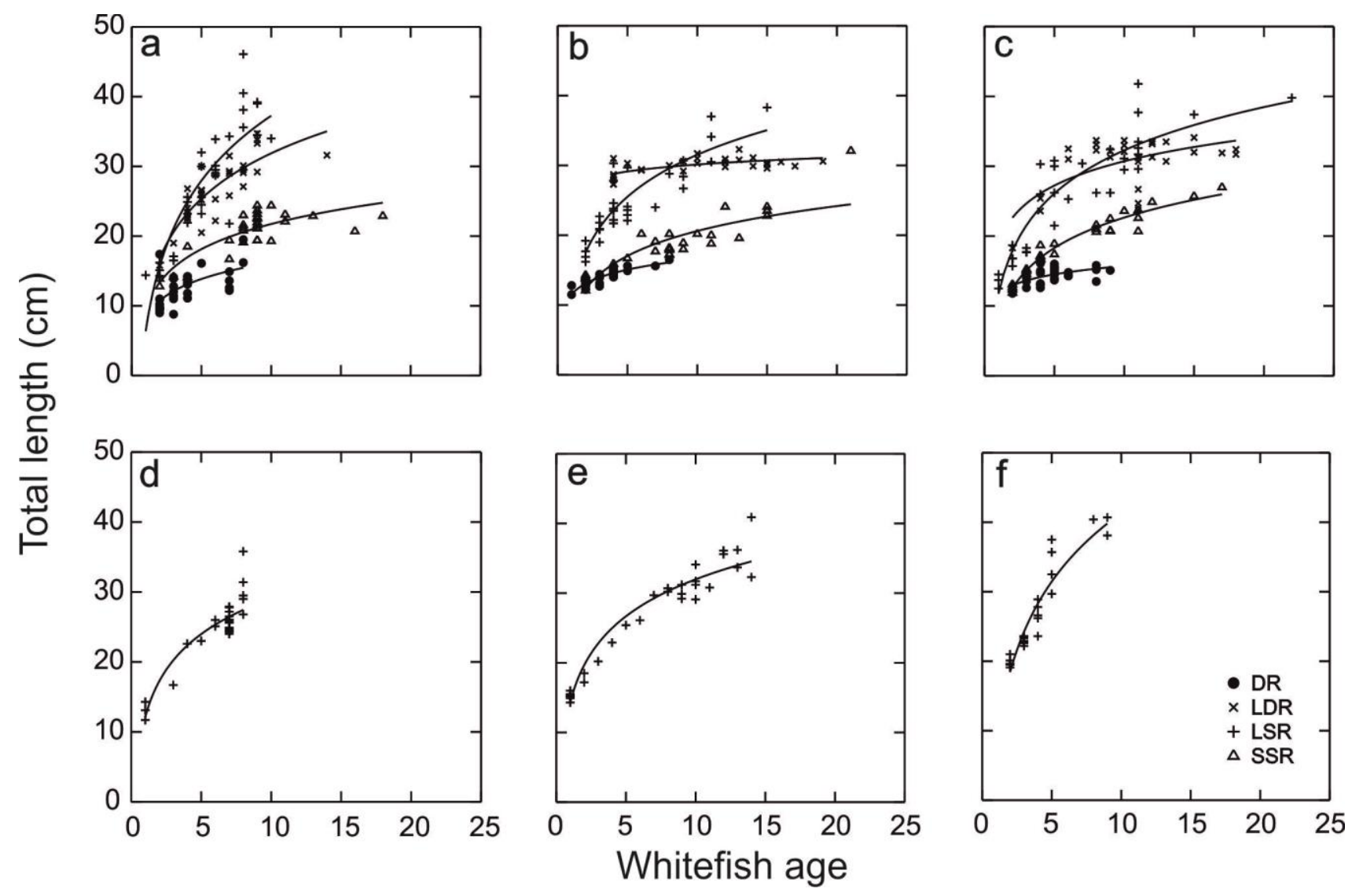

Figure S2. Non-linear von Bertalanffy growth curves for whitefish morphs in polymorphic Lakes Inari (a), Muddus (b), Paadar (c) as well as monomorphic Lakes Kilpis (d), Kuohkima (e) and Siilas (f). Whitefish morph abbreviations: DR; densely rakered whitefish, LDR; large densely rakered whitefish, LSR; large sparsely rakered whitefish, SSR; small sparsely rakered whitefish. For growth rate and infinity length, please see Table 3. 
Table S1. Loadings of first two axes of the principal component analysis. PC1 and PC2 explained 62\% and $20 \%$ of the total variation, respectively.

\begin{tabular}{lll}
\hline Ecomorphological trait & PC1 & PC2 \\
\hline Total length & 0.54538783 & -0.0400511 \\
Mass & 0.53009654 & -0.1016193 \\
Condition & 0.47438275 & 0.00851324 \\
Gill raker number & -0.0833555 & -0.9936502 \\
Age & 0.43538792 & -0.0256171 \\
\hline
\end{tabular}


Table S2. Diet of whitefish morphs in six study lakes, both at fine resolution, as well as combined into pelagic and benthic prey categories.

The 'Fish' category includes the benthic species alpine bullhead (Cottus poecilopus) and nine-spined stickleback (Pungitius pungitius). The 'Other' category includes benthic Ostracoda, Hydracarina, and macrophytes. Mean stomach fullness is calculated from all studied stomachs.

Whitefish morph abbreviations: DR; densely rakered whitefish, LDR; large densely rakered whitefish, LSR; large sparsely rakered whitefish, SSR; small sparsely rakered whitefish.

\begin{tabular}{|c|c|c|c|c|c|c|c|c|c|c|c|c|c|c|c|}
\hline & \multicolumn{4}{|c|}{ Inari } & \multicolumn{4}{|c|}{ Muddus } & \multicolumn{4}{|c|}{ Paadar } & \multirow{2}{*}{$\begin{array}{r}\text { Kilpis } \\
\text { LSR } \\
\end{array}$} & \multirow{2}{*}{$\begin{array}{r}\text { Kuohkima } \\
\text { LSR } \\
\end{array}$} & \multirow{2}{*}{$\begin{array}{r}\text { Siilas } \\
\text { LSR }\end{array}$} \\
\hline & DR & LDR & LSR & SSR & DR & LDR & LSR & SSR & DR & LDR & LSR & SSR & & & \\
\hline \multicolumn{16}{|l|}{ Pelagic prey } \\
\hline Terrestrial insects & 8.1 & 33.3 & & & 5.5 & 68.5 & & & 15.5 & 58.1 & 27.4 & & 8.6 & 11.8 & \\
\hline Cladocerans & 82.4 & 62.0 & 5.3 & & 46.5 & 6.2 & & & 13.4 & 11.0 & 11.6 & & 5.7 & 12.4 & 39.6 \\
\hline Pelagic copepods & 6.8 & & 1.1 & & 48.0 & 21.5 & & & 71.1 & 30.1 & 25.3 & & 35.7 & 21.9 & 2.0 \\
\hline \multicolumn{16}{|l|}{ Benthic prey } \\
\hline Megacyclops & & & 0.6 & 18.2 & & & & 6.6 & & & & 21.0 & 5.0 & & \\
\hline Eurycercus sp. & 2.7 & 3.7 & 42.0 & 27.7 & & & 56.8 & 8.3 & & & 12.6 & & 21.2 & 23.6 & 12.9 \\
\hline Chironomidae & & & 12.6 & 18.6 & & 1.5 & 11.6 & 53.2 & & & 5.3 & 44.6 & 10.9 & 6.3 & 36.5 \\
\hline Pisidium sp. & & & 8.4 & 34.7 & & & 1.4 & 24.9 & & & 3.2 & 34.4 & 5.9 & 3.5 & 0.8 \\
\hline Littoral snails & & & & & & & 8.2 & & & & 5.3 & & 5.3 & 3.8 & 7.2 \\
\hline Littoral insect larvae & & 0.9 & 29.2 & 0.7 & & & 15.8 & & & & 9.5 & & 0.1 & 13.9 & 1.0 \\
\hline Fish & & & 0.8 & & & & & & & & & & & 2.9 & \\
\hline Other & & & & & & 2.3 & 6.2 & 7.0 & & 0.7 & & & 1.6 & & \\
\hline Pelagic prey (\%) & 97.3 & 95.4 & 6.3 & 0.0 & 100.0 & 96.2 & 0.0 & 0.0 & 100.0 & 99.3 & 64.2 & 0.0 & 50.0 & 46.1 & 41.6 \\
\hline Benthic prey $(\%)$ & 2.7 & 4.6 & 93.7 & 100.0 & 0.0 & 3.8 & 100.0 & 100.0 & 0.0 & 0.7 & 35.8 & 100.0 & 50.0 & 53.9 & 58.4 \\
\hline Mean stomach fullness & 2.4 & 3.6 & 3.1 & 4.6 & 4.2 & 4.3 & 2.4 & 4.0 & 3.2 & 4.7 & 3.1 & 4.8 & 3.8 & 3.9 & 3.4 \\
\hline No of empty stomachs & 13 & 9 & 8 & 2 & 8 & 5 & 10 & 3 & 6 & 4 & 7 & 0 & 1 & 3 & 2 \\
\hline No of fish analysed & 31 & 30 & 31 & 30 & 29 & 30 & 30 & 29 & 30 & 29 & 31 & 30 & 30 & 31 & 29 \\
\hline
\end{tabular}


Table S3. Results of linear regression analyses between total mercury and age of whitefish by morph.

Whitefish morph abbreviations: DR; densely rakered whitefish, LDR; large densely rakered whitefish,

LSR; large sparsely rakered whitefish, SSR; small sparsely rakered whitefish.

\begin{tabular}{|c|c|c|c|c|c|}
\hline Lake and morph & Intercept & Slope & $F_{\text {(d.f.) }}$ & $\mathrm{R}^{2}$ & $\mathrm{p}$ \\
\hline \multicolumn{6}{|l|}{ Inari } \\
\hline DR & 0.175 & 0.065 & $78.8_{(1,29)}$ & 0.73 & $<0.0001$ \\
\hline LDR & 0.188 & 0.034 & $21.3_{(1,28)}$ & 0.43 & $<0.0001$ \\
\hline LSR & 0.129 & 0.010 & $2.2_{(1,29)}$ & 0.07 & 0.146 \\
\hline SSR & 0.222 & 0.018 & $16.2_{(1,28)}$ & 0.37 & $<0.0001$ \\
\hline \multicolumn{6}{|l|}{ Muddus } \\
\hline DR & 0.188 & 0.103 & $92.4_{(1,27)}$ & 0.77 & $<0.0001$ \\
\hline LDR & 0.099 & 0.047 & $320.7_{(1,28)}$ & 0.92 & $<0.0001$ \\
\hline LSR & 0.065 & 0.020 & $26.0_{(1,28)}$ & 0.48 & $<0.0001$ \\
\hline SSR & 0.314 & 0.008 & $3.2_{(1,27)}$ & 0.11 & 0.085 \\
\hline \multicolumn{6}{|l|}{ Paadar } \\
\hline DR & 0.299 & 0.038 & $38.1_{(1,28)}$ & 0.58 & $<0.0001$ \\
\hline LDR & 0.179 & 0.038 & $89.1_{(1,27)}$ & 0.78 & $<0.0001$ \\
\hline LSR & 0.112 & 0.020 & $63.6_{(1,29)}$ & 0.69 & $<0.0001$ \\
\hline SSR & 0.255 & 0.017 & $26.1_{(1,28)}$ & 0.48 & $<0.0001$ \\
\hline \multicolumn{6}{|l|}{ Kilpis } \\
\hline LSR & 0.144 & 0.004 & $1.5_{(1,28)}$ & 0.05 & 0.225 \\
\hline \multicolumn{6}{|l|}{ Kuohkima } \\
\hline LSR & 0.204 & 0.025 & $15.5_{(1,29)}$ & 0.35 & $<0.0001$ \\
\hline \multicolumn{6}{|l|}{ Siilas } \\
\hline LSR & 0.133 & 0.020 & $41.8_{(1,27)}$ & 0.61 & $<0.0001$ \\
\hline
\end{tabular}


Table S4. Results from multiple linear regression analyses for total mercury concentration in whitefish for individual lakes, and pooled across polymorphic and monomorphic lake types. A stepwise forward selection procedure was used, with limit to entry set at $\mathrm{p}<0.05$. Initial models contained the following factors: total length, condition factor, gill raker count, age, sex, sexual maturity, $\delta^{13} \mathrm{C}, \delta^{15} \mathrm{~N}$ and $\mathrm{C}: \mathrm{N}$ ratio.

\begin{tabular}{|c|c|c|c|c|c|c|}
\hline Lake & $\mathrm{R}^{2}$ & Factor & Coefficient & SE & $\mathrm{F}$ & $\mathrm{p}$ \\
\hline \multirow{4}{*}{$\begin{array}{l}\text { Inari } \\
(\mathrm{n}=122)\end{array}$} & \multirow[t]{4}{*}{0.62} & Condition factor & -0.304 & 0.121 & 6.3 & 0.013 \\
\hline & & Gill raker count & 0.011 & 0.001 & 67.8 & $<0.001$ \\
\hline & & $\delta^{13} \mathrm{C}$ & -0.017 & 0.006 & 8.5 & 0.004 \\
\hline & & Age & 0.034 & 0.003 & 119.7 & $<0.001$ \\
\hline \multirow{4}{*}{$\begin{array}{l}\text { Muddus } \\
(\mathrm{n}=118)\end{array}$} & \multirow[t]{4}{*}{0.70} & Total length & -0.010 & 0.003 & 12.3 & 0.001 \\
\hline & & Gill raker count & 0.019 & 0.002 & 121.6 & $<0.001$ \\
\hline & & $\delta^{15} \mathrm{~N}$ & 0.056 & 0.020 & 8.1 & 0.005 \\
\hline & & Age & 0.035 & 0.005 & 57.8 & $<0.001$ \\
\hline \multirow{3}{*}{$\begin{array}{l}\text { Paadar } \\
(\mathrm{n}=120)\end{array}$} & \multirow[t]{3}{*}{0.82} & Gill raker count & 0.014 & 0.001 & 226.9 & $<0.001$ \\
\hline & & $\delta^{15} \mathrm{~N}$ & 0.079 & 0.007 & 118.6 & $<0.001$ \\
\hline & & Age & 0.022 & 0.002 & 165.1 & $<0.001$ \\
\hline \multirow{8}{*}{$\begin{array}{l}\text { All polymorphic lakes } \\
(\mathrm{n}=360)\end{array}$} & \multirow[t]{8}{*}{0.71} & Total length & -0.004 & 0.002 & 7.0 & 0.009 \\
\hline & & Condition factor & -0.232 & 0.102 & 5.2 & 0.024 \\
\hline & & Gill raker count & 0.013 & 0.001 & 183.0 & $<0.001$ \\
\hline & & Sex & -0.026 & 0.010 & 7.2 & 0.007 \\
\hline & & Sexual maturity & 0.053 & 0.015 & 12.7 & $<0.001$ \\
\hline & & $\delta^{15} \mathrm{~N}$ & 0.022 & 0.007 & 9.2 & 0.003 \\
\hline & & $\delta^{13} \mathrm{C}$ & -0.013 & 0.003 & 13.5 & $<0.001$ \\
\hline & & Age & 0.029 & 0.002 & 148.1 & $<0.001$ \\
\hline $\begin{array}{l}\text { Kilpis } \\
(\mathrm{n}=30)\end{array}$ & 0.73 & $\delta^{13} \mathrm{C}$ & -0.012 & 0.001 & 75.5 & $<0.001$ \\
\hline $\begin{array}{l}\text { Kuohkima } \\
(\mathrm{n}=31)\end{array}$ & 0.35 & Age & 0.025 & 0.006 & 15.5 & $<0.001$ \\
\hline \multirow{2}{*}{$\begin{array}{l}\text { Siilas } \\
(\mathrm{n}=29)\end{array}$} & \multirow[t]{2}{*}{0.70} & Sex & -0.030 & 0.011 & 7.4 & 0.011 \\
\hline & & Age & 0.018 & 0.003 & 39.7 & $<0.001$ \\
\hline \multirow{3}{*}{$\begin{array}{l}\text { All monomorphic lakes } \\
(\mathrm{n}=90)\end{array}$} & \multirow[t]{3}{*}{0.39} & Sex & 0.050 & 0.020 & 6.6 & 0.012 \\
\hline & & $\delta^{15} \mathrm{~N}$ & -0.042 & 0.014 & 8.4 & 0.005 \\
\hline & & Age & 0.032 & 0.004 & 57.8 & $<0.001$ \\
\hline
\end{tabular}

